\title{
Jasmonate-mediated induced volatiles in the American cranberry, Vaccinium macrocarpon: from gene expression to organismal interactions
}

\author{
Cesar R. Rodriguez-Saona ${ }^{1}$, James Polashock ${ }^{2}$ and Edi A. Malo ${ }^{3}$ \\ 1 Department of Entomology, Philip E. Marucci Center for Blueberry and Cranberry Research, Chatsworth, NJ, USA \\ ${ }^{2}$ Genetic Improvement of Fruits and Vegetables Lab, Philip E. Marucci Center for Blueberry and Cranberry Research, United States Department of \\ Agriculture-Agricultural Research Service, Chatsworth, NJ, USA \\ ${ }^{3}$ Grupo de Ecología de Artrópodos y Manejo de plagas, El Colegio de la Frontera Sur, Tapachula, Chiapas, México
}

\section{Edited by:}

Erik Poelman, Wageningen University, Netherlands

\section{Reviewed by:}

Nicole M. Van Dam, Radboud

University Nijmegen, Netherlands

Colette Broekgaarden, Wageningen

University, Netherlands

*Correspondence:

Cesar R. Rodriguez-Saona, Philip E. Marucci Center for Blueberry and

Cranberry Research, 125A Lake

Oswego Road, Chatsworth, NJ

08019, USA.

e-mail: crodriguez@aesop.rutgers.edu
Jasmonates, i.e., jasmonic acid (JA) and methyl jasmonate (MeJA), are signaling hormones that regulate a large number of defense responses in plants which in turn affect the plants' interactions with herbivores and their natural enemies. Here, we investigated the effect of jasmonates on the emission of volatiles in the American cranberry, Vaccinium macrocarpon, at different levels of biological organization from gene expression to organismal interactions. At the molecular level, four genes (BCS, LLS, NER1, and TPS21) responded significantly to gypsy moth larval feeding, MeJA, and mechanical wounding, but to different degrees. The most dramatic changes in expression of BCS and TPS21 (genes in the sesquiterpenoid pathway) were when treated with MeJA. Gypsy moth-damaged and MeJA-treated plants also had significantly elevated expression of LLS and NER1 (genes in the monoterpene and homoterpene biosynthesis pathways, respectively). At the biochemical level, MeJA induced a complex blend of monoterpene and sesquiterpene compounds that differed from gypsy moth and mechanical damage, and followed a diurnal pattern of emission. At the organismal level, numbers of Sparganothis sulfureana moths were lower while numbers of parasitic wasps were higher on sticky traps near MeJA-treated cranberry plants than those near untreated plants. Out of 11 leaf volatiles tested, (Z)-3-hexenyl acetate, linalool, and linalool oxide elicited strong antennal (EAG) responses from $S$. sulfureana, whereas sesquiterpenes elicited weak EAG responses. In addition, mortality of S. sulfureana larvae increased by about $43 \%$ in JA treated cranberry plants as compared with untreated plants, indicating a relationship among adult preference, antennal sensitivity to plant odors, and offspring performance. This study highlights the role of the jasmonatedependent defensive pathway in the emissions of herbivore-induced volatiles in cranberries and its importance in multi-trophic level interactions.

Keywords: methyl jasmonate, jasmonic acid, herbivore-induced plant volatiles, Sparganothis sulfureana, electroantennograms, multi-trophic interactions

\section{INTRODUCTION}

Plants can sometimes change their phenotype after herbivore feeding damage by becoming more protected from future enemy attacks (Karban and Baldwin, 1997; Walling, 2000; Heil, 2010). These induced phenotypic changes can reduce the performance of herbivores or alter their behavior, i.e., reduce the herbivore's feeding or oviposition on plants (Agrawal, 1998; Denno et al., 2000; De Moraes et al., 2001; Kessler and Baldwin, 2001; Van Zandt and Agrawal, 2004; Viswanathan et al., 2005), and can thus be classified as direct defenses if they provide a fitness benefit to plants (Agrawal, 1998, 2000). They can also indirectly defend plants by changing the behavior of the herbivores' natural enemies (Price et al., 1980). One such indirect defense is the emission of volatiles - so-called herbivore-induced plant volatiles (HIPVs) that attract predators and parasitoids of insect herbivores to the attacked plant (Turlings et al., 1990; Vet and Dicke, 1992; Dicke and Vet, 1999). Manipulation of these defensive traits in plants can serve as a natural pest control tactic in agriculture (Thaler, 1999a; Rodriguez-Saona et al., 2012).

An important signaling pathway involved in the induction of plant defenses, including HIPV emissions, is the octadecanoid pathway (Karban and Baldwin, 1997; Arimura et al., 2005). In many plants, activation of the octadecanoid pathway by herbivore feeding may lead to increased production of the plant growth regulator, jasmonic acid (JA) (Farmer et al., 1992; Staswick and Lehman, 1999), which in turn can elicit multiple direct and indirect defenses in plants (Karban and Baldwin, 1997). For example, increases in HIPV emissions similar to those induced by insect feeding have been reported in response to exogenous applications of jasmonates, i.e., JA or its volatile methyl ester methyl jasmonate (MeJA), in many plant species including gerbera, Gerbera jamesonii Bolus (Gols et al., 1999), 
cotton, Gossypium hirsutum L. (Rodriguez-Saona et al., 2001), Manchurian ash, Fraxinus mandshurica Rupr. (Rodriguez-Saona et al., 2006), and sacred datura, Datura wrightii Regel (Hare, 2007).

Activation of the octadecanoid pathway by jasmonate treatment is known to affect the preference and performance of herbivores on plants. Thaler et al. (2001), for example, found fewer caterpillars, flea beetles, aphids, and thrips on tomato plants that were sprayed with JA. Manduca quinquemaculata Haworth oviposition was reduced when Nicotiana attenuata Torr ex. S. Watts plants were treated with MeJA (Kessler and Baldwin, 2001). Similarly, Bruinsma et al. (2007) showed that two species of cabbage white butterflies, Pieris rapae L. and P. brassicae L., laid fewer eggs on JA-treated Brussels sprouts, Brassica oleracea L., plants compared to untreated plants. Pieris rapae also preferred untreated leaves over JA-treated leaves of black mustard plants, Brassica nigra L., for oviposition (Bruinsma et al., 2008). Jasmonateinduced changes can also affect members of higher trophic levels. For example, JA treatment increased parasitism of caterpillars in tomato fields (Thaler, 1999b), but negatively affected predatory hoverflies due to a decrease in prey (aphid) abundance (Thaler, 2002). JA or MeJA also induced the emission of plant volatiles that attracted predatory mites (Dicke et al., 1999; Gols et al., 2003).

Studies that integrate multiple research approaches, such as gene expression, metabolite induction, and ecological interactions, are needed for a better understanding of plant interactions with arthropods across different levels of biological organization (Zheng and Dicke, 2008). Previously, we showed that gypsy moth, Lymantria dispar L. (Lep., Lymantriidae), larval feeding, and MeJA induce emissions of several monoterpenes and sesquiterpenes in a perennial ericaceous crop, the American cranberry (Vaccinium macrocarpon Ait.) (Rodriguez-Saona et al., 2011). In the present study, we linked volatile induction with transcriptional induction and organismal level interactions by investigating the effects of jasmonates on the up-regulation of several key terpene biosynthesis genes, induced volatile emissions, and the preference-performance of a polyphagous herbivore, Sparganothis sulfureana Clemens (Sparganothis fruitworm; Lep., Tortricidae), in cranberries. Sparganothis sulfureana is an important pest of cranberries in the United States (USA); in spring, the overwintered first instar larvae feed on foliage, adults emerge in late spring to mid-summer, and in June to early July second generation larvae feed on foliage and burrow into developing fruit (Beckwith, 1938; Averill and Sylvia, 1998). Specifically, we conducted studies to: (1) determine the effects of MeJA, gypsy moth larval feeding, and mechanical wounding on expression of eight genes involved in terpenoid biosynthesis; (2) compare the volatile emissions of cranberries in response to MeJA application, gypsy moth feeding, and mechanical wounding, and investigate the diurnal pattern of volatile emissions; (3) examine the response of key herbivores ( $S$. sulfureana and leafhoppers) and natural enemies [hoverflies (Dip., Syrphidae), minute pirate bugs (Hem., Anthocoridae), spiders (Araneae), and parasitic wasps (Hymenoptera)] to MeJA application on cranberry plants; (4) test the effect of JA-treated cranberry foliage on S. sulfureana larval mortality; and, (5) investigate the electrophysiological response of S. sulfureana antennae (EAG) to various cranberry leaf volatiles.

\section{MATERIALS AND METHODS PLANTS AND INSECTS}

Cranberries are propagated clonally and grow from single shoots by producing new uprights and runners. Cranberries, V. macrocarpon var. Stevens, were grown from rooted cuttings in $10 \mathrm{~cm}$ pots in a greenhouse $\left(22 \pm 2^{\circ} \mathrm{C} ; 70 \pm 10 \% \mathrm{RH} ; 15: 9 \mathrm{~L}: \mathrm{D}\right)$ at the Rutgers P. E. Marucci Center for Blueberry and Cranberry Research and Extension (Chatsworth, NJ, USA). Three cuttings were rooted per pot. Plants were allowed to grow in the greenhouse for at least a year before being used in experiments, and were fertilized biweekly with PRO-SOL 20-20-20 N-P-K All Purpose Plant Food (Pro Sol Inc., Ozark, AL, USA) at a rate of $165 \mathrm{ppm} \mathrm{N}$ and watered daily. At the time of bioassays, plants from each rooted cutting contained 3-5 uprights and runners. Runners were pruned as needed, and all plants were at the vegetative stage and insect-free when used in experiments.

Lymantria dispar caterpillars and Sparganothis sulfureana adults and caterpillars were obtained from a laboratory colony maintained at the Rutgers Marucci Center. Caterpillars were reared on a wheat germ diet (Bell et al., 1981) in $30 \mathrm{ml}$ clear plastic cups at $24 \pm 1^{\circ} \mathrm{C}, 65 \% \mathrm{RH}$, and 14:10 L:D. Field-collected caterpillars were added yearly to the laboratory colony.

\section{TREATMENT APPLICATIONS}

Plants in each pot were bagged with a spun polyester sleeve (Rockingham Opportunities Corp., Reidsville, NC, USA) and then subjected to one of the following treatments:

(1) Jasmonate treatment: potted plants were sprayed with $1 \mathrm{ml}$ of a $1 \mathrm{mM}$ JA or MeJA solution (Sigma-Aldrich, St. Louis, MO, USA) dissolved in $0.4 \%$ acetone or $0.1 \%$ Tween 20 , respectively. Treated plants were used for bioassays (gene expression, volatile collections, and field experiments, see below) $\sim 16 \mathrm{~h}$ after jasmonate application (unless otherwise stated); this time period was sufficient to induce a volatile response from cranberry leaves in previous studies (Rodriguez-Saona et al., 2011).

(2) Caterpillar treatment: cranberry leaves were damaged by third-fourth instar gypsy moth caterpillars. Four or eight caterpillars were placed on plants and allowed to feed for 2 days before used in bioassays (gene expression and volatile collections); this amount of feeding time by gypsy moth was sufficient to induce a volatile response from cranberry leaves (Rodriguez-Saona et al., 2011).

(3) Mechanical treatment: mechanical damage was inflicted for 2 days by cutting the tips of 40 leaves (20 leaves were mechanically damaged on day 1 and 20 leaves on day 2) with scissors to simulate the amount of leaf area removed by gypsy moth caterpillars. Following, plants were used for gene expression and volatile collections.

(4) Control treatment: plants were either sprayed with $1 \mathrm{ml}$ of distilled water with $0.4 \%$ acetone, $0.1 \%$ Tween 20 , or received no treatment.

Bags were opened just prior to, and closed soon after, treatment. 


\section{GENE EXPRESSION ANALYSIS}

Leaves were harvested from jasmonate (MeJA)-treated, caterpillardamaged, mechanically wounded, and control (Tween) plants ( $N=3$ individual plants or biological replicates per treatment). We used eight rather than four gypsy moth caterpillars in these studies because this herbivore density induces a stronger volatile response in cranberries (see Results). We also harvested undamaged leaves from plants upon which gypsy moths fed and from mechanically wounded plants (systemic response). All samples were collected at 10:00. RNA was immediately extracted from the harvested leaves using the RNeasy Plant Mini Kit (Qiagen; Valencia, CA, USA) according to the manufacturer's directions. The total RNA was eluted in $100 \mu \mathrm{l}$ sterile $\mathrm{dH}_{2} \mathrm{O}$ and quantified using the ND-1000 Nanodrop Spectrophotometer (Nanodrop Products; Wilmington, DE, USA). The cDNA was synthesized using $100 \mathrm{ng}$ of RNA per reaction and the Superscript VILO cDNA Synthesis kit (Invitrogen; Carlsbad, CA, USA) according to the manufacturer's protocol.

The genes targeted for real-time PCR and the primers used for each are listed in Table 1. The eight genes were selected for expression analysis based partly on published reports of terpenoid biosynthesis gene induction when jasmonate treated or in response to herbivores and partly on our own previous work on the volatiles that cranberry plants emit (Rodriguez-Saona et al., 2011). These include (-)- $\beta$-caryophyllene synthase (BCS), farnesyl diphosphate synthase (FDS), R-linalool synthase (LLS), (E)-4-hydroxy-3-methylbut-2-enyl-diphosphate synthase (MDS), $(3 S, 6 E)$-nerolidol synthase (NER1), phosphomevalonate kinase $(P M K)$, terpene 1,8 -cineole synthase (TPS), and $\alpha$-humulene/ $\beta$ caryophyllene synthase (TPS21). Actin (ACT) and RNA Helicase 8 (RH8) were used as endogenous controls. The gene sequences were selected from an assembled total genome sequence of cranberry (Georgi et al., 2013 and unpublished). Each target gene sequence was identified by homology to published sequences from other plant species. The primers were designed using the predicted coding sequence of each gene and the Primer Express 3.0 software (Applied Biosystems; Foster City, CA, USA). Real-time PCR reactions were set up using the Power SYBR Green PCR Master Mix (Applied Biosystems) according to manufacturer's directions and run on an Applied Biosystems 7500 real-time PCR machine. Thermocycling conditions were $50^{\circ} \mathrm{C}-2 \mathrm{~min}, 95^{\circ} \mathrm{C}-10 \mathrm{~min}$ followed by 40 cycles at $95^{\circ} \mathrm{C}-15 \mathrm{~s}, 60^{\circ} \mathrm{C}-1$ min with melt curve set at $95^{\circ} \mathrm{C}-15 \mathrm{~s}, 60^{\circ} \mathrm{C}-1 \mathrm{~min}, 95^{\circ} \mathrm{C}-30 \mathrm{~s}, 60^{\circ} \mathrm{C}-15 \mathrm{~s}$. There were three biological replicates (individual plants) of each sample and three technical replicates were run for each biological replicate. The technical replicates for each biological replicate were averaged. Relative expression levels were calculated by the $\Delta \Delta C T$ method using the DataAssist 3.0 software package (Applied Biosystems) and using $A C T$ and $R H 8$ to normalize the expression.

\section{HEADSPACE COLLECTION}

Volatiles emitted from cranberry plants that were either damaged by four or eight gypsy moth caterpillars, treated with MeJA, or left undamaged were collected using a push-pull volatile collection system (Tholl and Röse, 2006; Rodriguez-Saona, 2011) in a greenhouse (under conditions described above). The system consisted of four $4 \mathrm{~L}$ glass chambers (Analytical Research Systems, Inc., Gainesville, FL, USA). The chambers had a guillotine-like split plate with a hole in the center at the base that closed loosely around the stem of the plant. Incoming purified air entered each chamber at $2 \mathrm{~L} \mathrm{~min}^{-1}$ and was pulled through a filter trap containing $30 \mathrm{mg}$ of Super-Q adsorbent (Alltech; Nicholasville, KY, USA) with a vacuum pump at $1 \mathrm{~L} \mathrm{~min}^{-1}$. Volatile collections were initiated at 10:00. After $4 \mathrm{~h}$ of volatile collection, fresh weight of plants was measured to account for differences in plant size. Each treatment was replicated four times.

To determine the diurnal pattern of emissions, volatiles were collected from MeJA-treated at five different times of the day (06:00-10:00, 10:00-14:00, 14:00-18:00, 18:00-22:00, and 22:0006:00). The experiment was replicated three times.

\section{VOLATILE ANALYSIS}

Collected volatiles were desorbed from the Super-Q traps with dichloromethane $(150 \mu \mathrm{l})$ and added $400 \mathrm{ng}$ of $n$-octane (SigmaAldrich; St. Louis, MO, USA) as internal standard (IS). Headspace samples ( $1 \mu \mathrm{l}$ aliquots) were injected onto a Hewlett Packard 6890 Series Gas Chromatograph (GC) equipped with a flame ionization detector and a HP-1 column $(10 \mathrm{~m} \times 0.53 \mathrm{~mm} \mathrm{ID} \times 2.65 \mu \mathrm{m}$ film thickness; Agilent Technologies, Palo Alto, CA, USA), with helium flow of $5 \mathrm{ml} \mathrm{min}{ }^{-1}$. The temperature program started at $40^{\circ} \mathrm{C}(1 \mathrm{~min}$ hold $)$, and rose at $14^{\circ} \mathrm{C} \mathrm{min}^{-1}$ to $180^{\circ} \mathrm{C}(2 \mathrm{~min}$ hold $)$, then at $40^{\circ} \mathrm{C} \mathrm{min}^{-1}$ to $200^{\circ} \mathrm{C}(2 \mathrm{~min}$ hold $)$. Compounds (relative

Table 1 | Targets used for real-time qPCR, enzyme commission (EC) numbers and primer sequences.

\begin{tabular}{|c|c|c|c|}
\hline Target (abbreviation) & EC number & Real-time F primer & Real-time R primer \\
\hline Farnesyl diphosphate synthase (FDS) & 2.5.1.10 & CGAGGTCAGCCATGTTGGTA & CCATCATTTGCAGCAATCAAA \\
\hline (E)-4-hydroxy-3-methylbut-2-enyl-diphosphate synthase (MDS) & 1.17.7.1 & GCACAGGCGTTACTTCGATTT & CCCTCTTTTTGGATTGGCAAT \\
\hline Phosphomevalonate kinase (PMK) & 2.7 .4 .2 & TTCССТTCCACCGTTTACATCT & AGGCTTGCGAGTTTCTGAATTT \\
\hline Terpene 1,8-cineole synthase (TPS) & 4.2.3.108 & GGTGGGATATAACTGCAATGGAA & TGAAAAGAGCAAGGAAGCAAATC \\
\hline (-)- $\beta$-Caryophyllene synthase (BCS) & 4.2 .3 .57 & TCCGGTGGTTACAAAATGCTT & CACCAAATCCCCCATGACA \\
\hline$R$-Linalool synthase (LLS) & 4.2 .3 .26 & GGGCAAGTTTGTGCAATGC & GGCAACTGCCCAGAAGCA \\
\hline$\alpha$-Humulene/ $\beta$-caryophyllene synthase (TPS21) & 4.2.3. & TCCGGTGGTTACAAAATGCTT & CACCAAATCCCCCATGACA \\
\hline (3S,6E)-nerolidol synthase (NER1) & 4.2 .3 .48 & GGGCAAGTTTGTGCAATGC & GGCAACTGCCCAGAAGCA \\
\hline Actin $(\mathrm{ACT})$ & - & TTCACCACCACGGCTGAAC & AGCCACGTATGCAAGCTTTTC \\
\hline RNA Helicase-Like 8 (RH8) & 3.6.4.13 & TGCCAAGATGCTTCAAGATCA & GCATGCACCATTCCGAAAAT \\
\hline
\end{tabular}


amounts) were quantified based on comparison of peak areas with that of the IS without FID response factor correction.

Identification of compounds was performed on a Varian 3400 GC coupled to a Finnigan MAT 8230 mass spectrometer (MS) equipped with a MDN-5S column $(30 \mathrm{~m} \times 0.32 \mathrm{~mm} \mathrm{ID} \times 0.25 \mu \mathrm{m}$ film thickness; Supelco, Bellefonte, PA, USA). The temperature program was initiated at $35^{\circ} \mathrm{C}(1 \mathrm{~min}$ hold $)$, rose at $4^{\circ} \mathrm{C} \mathrm{min}^{-1}$ to $170^{\circ} \mathrm{C}$, then at $15^{\circ} \mathrm{C} \mathrm{min}^{-1}$ to $280^{\circ} \mathrm{C}$. The MS data were recorded and processed in a Finnigan MAT SS300 data system. The eluted compounds were identified by comparing the mass spectra with those from NIST library spectra and comparison of their retention times to those of commercially available compounds (Rodriguez-Saona et al., 2011).

\section{ELECTROANTENNOGRAPHIC ANALYSIS}

The relative antennal receptivity of adult males and females of S. sulfureana to 11 synthetic volatile compounds emitted from cranberry plants (this study; Rodriguez-Saona et al., 2011) was compared by EAG. The insect head was cut off carefully, and a reference electrode was inserted into its base with a glass capillary filled with physiological saline solution (Malo et al., 2004). The distal end of the antenna was inserted into the tip of the recording glass capillary electrode. EAGs were measured using 5-10 moths of each sex per volatile compound. The signals generated by the antennae were passed through a high-impedance amplifier (NL 1200; Syntech, Hilversum, Netherlands) and displayed on a monitor by Syntech software for processing EAG signals. A stimulus flow controller (CS-05; Syntech) was used to generate a stimulus at 1 min intervals. A current of humidified pure air $\left(0.7 \mathrm{~L} \mathrm{~min}^{-1}\right)$ was constantly directed onto the antenna through a 10 -mm-diameter glass tube. Dilutions of the synthetic compounds were prepared in HPLC-grade hexane to make $10 \mu \mathrm{g}$ per $\mu \mathrm{l}$ solutions. A standard aliquot $(1 \mu \mathrm{l})$ of each test dilution was pipetted onto a piece of filter paper $(0.5 \mathrm{~cm} \times 3.0 \mathrm{~cm}$; Whatman, No. 1$)$, exposed to air for $20 \mathrm{~s}$ to allow the solvent to evaporate, then inserted into a glass Pasteur pipette or sample cartridge, and left for $40 \mathrm{~s}$ before applying to antennae. A new cartridge was prepared for each insect. To present a stimulus, the pipette tip containing the test compound was inserted through a side hole located at the midpoint of a glass tube through which humidified pure air flowed at $0.5 \mathrm{~L} \mathrm{~min}^{-1}$. The duration of stimulus was $1 \mathrm{~s}$. The continuous flow of clean air through the airflow tube and over the preparation ensured that odors were removed immediately from the vicinity. The synthetic compounds $(10 \mu \mathrm{g})$ were presented in random order. Control stimuli (air or filter paper with hexane) were presented at the beginning and end of each EAG analysis. Synthetic chemicals were purchased from Sigma-Aldrich and Bedoukian Research (Danbury, CT, USA), and the purities were $>95 \%$ based on the results with GC.

\section{ECOLOGICAL LEVEL ANALYSIS}

The goal of this field study was to investigate the response of arthropods to MeJA-treated cranberry plants. The experiment was conducted in June-July of 2009 to coincide with S. sulfureana peak flight activity (Averill and Sylvia, 1998), on a commercial cranberry farm located in Chatsworth, New Jersey $\left(39^{\circ} 72^{\prime} \mathrm{N}, 74^{\circ} 50^{\prime}\right.$ $\mathrm{W})$, using potted cranberry plants (grown as described above).
Potted plants were either treated with MeJA or left untreated (controls) $(N=15$ pots per treatment). Pots were placed in a $5 \times 6$ grid pattern within an established cranberry bed ( $\sim 2 \mathrm{ha})$, and were separated by at least $10 \mathrm{~m}$ from each other. Treatments were assigned randomly to each location and applied at 17:00. The following morning (08:00), a sticky trap was placed in each pot to monitor abundances of all colonizing arthropods. The sticky traps were $5 \mathrm{~cm} \times 5 \mathrm{~cm}$ pieces of green cardboard, covered on both sides (e.g., bi-directional trap) with a thin layer of Tangle-Trap (The Tanglefoot Co., Grand Rapids, MI, USA), and mounted on wooden stakes about $10 \mathrm{~cm}$ from the soil, such that the traps were next to but not touching the plants. Traps were left in the field for $48 \mathrm{~h}$, after which they were removed, wrapped in plastic film, and stored in a refrigerator $\left(4^{\circ} \mathrm{C}\right)$ for arthropod identification. The entire experiment was replicated three times with a new set of plants each time.

To determine the effects of jasmonate-mediated responses in cranberries on S. sulfureana larval survival, an experiment was conducted in a cranberry bed located at the Rutgers Marucci Center. Plots $(60 \mathrm{~cm} \times 60 \mathrm{~cm})$ were treated with JA or left untreated (controls), replicated three times, and separated by $60 \mathrm{~cm}$. Applications were made with an R\&D (Bellspray Inc., Opelousas, LA, USA) $\mathrm{CO}_{2}$ backpack sprayer, using a $1 \mathrm{~L}$ plastic bottle, calibrated to deliver $418 \mathrm{~L}$ per hectare at $241 \mathrm{kPa}(\sim 15.4 \mathrm{ml}$ per plot). Treatments were applied at 06:00 in early August, 2007. Four hours after treatment, five uprights were randomly collected from each plot and inserted in florists' water picks, enclosed in a ventilated 40-dram plastic vial, and secured on polystyrene foam trays. Each replicate consisted of a total of 10 vials per treatment $(N=30$ vials per treatment). Four $S$. sulfureana neonates were added to each vial, and vials were placed in the laboratory at $\sim 25^{\circ} \mathrm{C}$. The number of live larvae was recorded after 7 days.

To confirm that the effects of the JA treatment on S. sulfureana larval survival were the result of plant effects rather than any direct toxic effects of JA, an additional experiment was conducted to test the toxicity of JA to S. sulfureana neonates. Sparganothis sulfureana neonates were placed in $30 \mathrm{ml}$ plastic cups (one neonate per cup), containing $10 \mathrm{ml}$ of wheat germ diet. The diet in each cup was sprayed with either $1 \mathrm{mM}$ JA solution with $0.4 \%$ acetone or distilled water with $0.4 \%$ acetone $4 \mathrm{~h}$ prior to placing the caterpillars $(N=50$ cups per treatment). The number of live larvae was recorded after 7 days.

\section{DATA ANALYSIS}

The normalized gene expression levels were log-transformed, to satisfy the homogeneity of variance assumption for ANOVA. However, even with this transformation, responses of two genes (BCS and TPS21) to one treatment (systemic response in mechanically wounded plants) had excessively large variances, so were excluded from the analyses. Linear mixed models were fit with the lme4 package (Bates et al., 2011) in R (R Development Core Team, 2012) (with biological replicate as a random effect) to a subset of genes whose expression levels changed over treatments, means separations within a gene were done using the multcomp package (Hothorn et al., 2008).

Principal component analysis (PCA) was used to visualize overall differences among blends emitted from each treatment (gypsy moth feeding, MeJA, mechanical wounding, and control) using 
Minitab v. 16 (Minitab Inc., State College, PA, USA). PCA was initially performed on the data because individual volatile compounds within blends are not independent (Hare, 2011). We also used multivariate analysis of variance (MANOVA; Minitab) to analyze the effects of treatment on volatile emissions. Volatile compounds were grouped into esters, monoterpenes, homoterpenes, sesquiterpenes, or others (only groups containing more than two compounds were considered for MANOVA). A significant MANOVA was followed by ANOVA (Minitab) to determine which compounds within a group were affected by treatment (Scheiner, 2001). Similarly, PCA and ANOVA were used to test the effect of time of day on volatiles emissions from MeJA-treated plants (06:00-10:00, 10:00-14:00, 14:00-18:00, 18:00-22:00, and 22:0006:00). Volatile emissions data were either $\ln (x)$ - or $\ln (x+0.5)$ transformed prior to analysis to satisfy assumptions of normality and homogeneity of variances. Differences in the emissions of individual compounds among treatments were analyzed by Tukey post hoc comparisons $(\alpha=0.05)$.

Sticky trap data were first analyzed by functional group, i.e., herbivores and natural enemies (predators and parasitoids), using MANOVA. MANOVA was initially performed on the data because densities of individual arthropod groups are not independent (Scheiner, 2001). The model included treatment (MeJA versus control), time of year (date), and treatment $\times$ date. A significant MANOVA was followed by ANOVA for individual arthropod groups. When needed, data were $\ln (x)$ or $\ln (x+0.5)$-transformed before analysis. Mortality data were arcsine square-root transformed before analysis with ANOVA. A chi-square test was used to determine differences in S. sulfureana mortality rate when fed diets sprayed with JA versus unsprayed diets.

The values of the EAG depolarization amplitude after exposure to the volatile compounds were transformed $[\ln (x+0.5)]$ prior to analysis with two-way ANOVA with sex of insect and type of chemical compound as the two factors. Significant ANOVA results were followed by Tukey test for means comparison.

\section{RESULTS}

\section{GENE EXPRESSION}

To determine if the various treatments induced expression of key enzymes in the terpenoid biosynthetic pathway, we tested the relative expression levels of eight selected genes - BCS, FDS, LLS, MDS, NER1, PMK, TPS, TPS21 - using real-time PCR. Four of the genes tested responded significantly to gypsy moth larval feeding, MeJA, and mechanical wounding (BCS, LLS, NER1, and TPS21), but to different degrees (Figure 1). The most dramatic changes in expression of BCS and TPS21 were when treated with MeJA. All

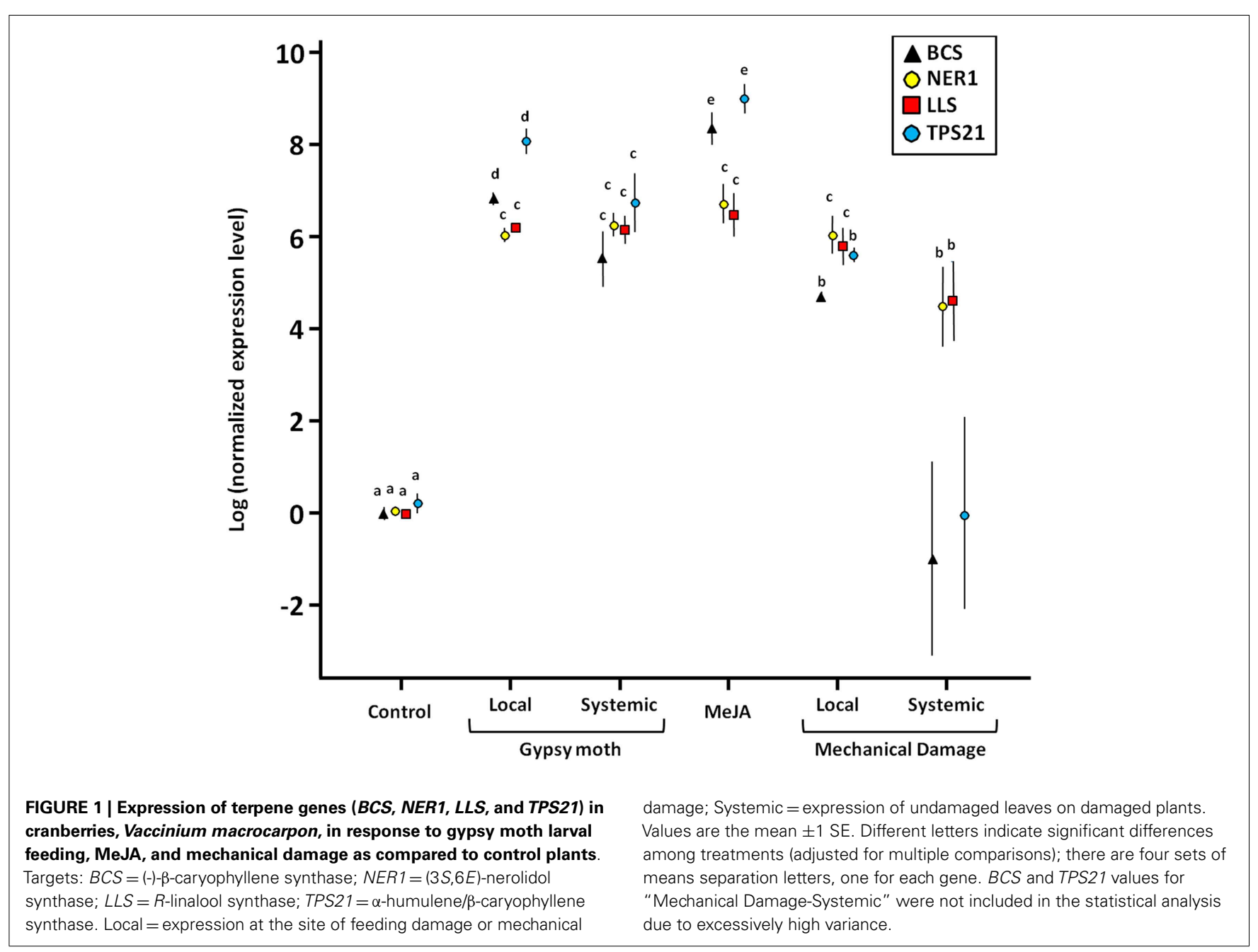


MeJA-treated plants also had significantly elevated expression of $L L S$ and NER1. For those genes that responded to gypsy moth feeding (BCS, LLS, NER, and TPS21), the changes in gene expression were also evident in the undamaged tissue on the same plant. This was also true in mechanically wounded plants, but only for NER1 and $L L S$. The undamaged leaves from the mechanically wounded plants had a wide variance in gene expression for BCS and TPS21. Expression of the other four genes tested (FDS, MDS, PMK, TPS) were unchanged for any of the treatments $(P>0.05$; data not shown).

\section{VOLATILE EMISSIONS}

Cranberry plants responded to gypsy moth feeding in a density-dependent manner such that volatile emissions were $\sim 2.5$ times greater when plants were damaged by eight caterpillars as compared with four caterpillars (four caterpillars [mean emissions in $\mathrm{ng} \mathrm{h}^{-1} \mathrm{~g}^{-1}$ fresh tissue $\left.\pm \mathrm{SE}\right]: 81.9 \pm 24$.1; eight caterpillars: $199.9 \pm 18.4 ; F=10.41, d f=1.6, P=0.018)$. Eleven out of 22 volatiles were significantly induced by herbivory from cranberry plants compared with undamaged plants (Table 2); with eucalyptol/limonene, linalool, DMNT, indole, $\beta$-caryophyllene, $\alpha$-humulene, and germacrene-D emitted in highest quantities.

Total emissions of volatiles were 9 and 14-fold higher in gypsy moth-damaged (eight caterpillars) and MeJA-treated plants than in control plants, respectively; whereas emissions from mechanically wounded plants were variable and not significantly different from control plants (Table 2). The PCA resulted in a model with the first two PC components explaining $65.7 \%$ of the total

Table 2 | Volatiles identified in the headspace of cranberry, Vaccinium macrocarpon, plants damaged by eight gypsy moth larvae, sprayed with $1 \mathrm{mM}$ MeJA solution, mechanically damaged with scissors, or left undamaged (control) ${ }^{1}$.

\begin{tabular}{|c|c|c|c|c|c|c|c|c|c|c|}
\hline Compound & \multicolumn{2}{|c|}{ Control $^{2}$} & \multicolumn{2}{|c|}{ Gypsy moth } & \multicolumn{2}{|c|}{ MeJA } & \multicolumn{2}{|c|}{ Mechanical wounding } & $F^{3}$ & $\boldsymbol{P}$ \\
\hline \multicolumn{11}{|c|}{ LIPOXYGENASE PATHWAY PRODUCTS } \\
\hline (Z)-3-Hexenyl acetate ${ }^{4}$ & $3.8 \pm 0.7$ & $(18) b$ & $8.7 \pm 1.0$ & $(4) a b$ & $39.2 \pm 31.0$ & (13)ab & $313.5 \pm 170.6$ & $(92) a$ & 4.88 & 0.019 \\
\hline \multicolumn{11}{|c|}{ ISOPRENOID PATHWAY PRODUCTS } \\
\hline \multicolumn{11}{|c|}{ Monoterpenes } \\
\hline$\alpha$-Pinene & n.d. & $b$ & n.d. & $\mathrm{b}$ & $1.5 \pm 0.6$ & $(<1) \mathrm{a}$ & n.d. & $\mathrm{b}$ & 8.10 & 0.003 \\
\hline Camphene & $1.5 \pm 0.1$ & (7) bc & $5.1 \pm 0.7$ & (3)a & $3.0 \pm 0.5$ & $(1) a b$ & $0.7 \pm 0.5$ & $(<1) \mathrm{c}$ & 10.87 & 0.001 \\
\hline Sabinene & $0.5 \pm 0.5$ & $(2) \mathrm{b}$ & $4.3 \pm 0.8$ & (2)a & $3.3 \pm 0.5$ & (1)ab & $9.9 \pm 5.2$ & (3)a & 5.56 & 0.013 \\
\hline$\beta$-Pinene & n.d. & $b$ & n.d. & $b$ & $1.3 \pm 0.4$ & $(<1) \mathrm{a}$ & n.d. & $b$ & 8.93 & 0.002 \\
\hline Myrcene & n.d. & $b$ & $2.3 \pm 0.3$ & (1)ab & $1.0 \pm 0.6$ & $(<1) \mathrm{a}$ & $0.3 \pm 0.3$ & $(<1) \mathrm{b}$ & 7.01 & 0.006 \\
\hline Eucalyptol/Limonene 5 & $0.8 \pm 0.4$ & $(4) b$ & $9.2 \pm 3.6$ & (5)a & $3.4 \pm 0.8$ & $(1) a b$ & $7.3 \pm 3.5$ & (2)ab & 5.22 & 0.015 \\
\hline Linalool oxide & n.d. & $\mathrm{b}$ & $1.4 \pm 0.8$ & (1)ab & $1.5 \pm 0.3$ & $(<1) \mathrm{a}$ & n.d. & $\mathrm{b}$ & 5.93 & 0.01 \\
\hline Linalool & $3.9 \pm 0.4$ & $(18) b$ & $23.3 \pm 3.6$ & $(12) a$ & $42.6 \pm 10.3$ & $(14) a$ & $3.4 \pm 0.8$ & $(1) b$ & 35.93 & $<0.001$ \\
\hline Borneol & n.d. & a & n.d. & a & $0.4 \pm 0.4$ & $(<1) a$ & n.d. & a & 1.00 & 0.426 \\
\hline \multicolumn{11}{|l|}{ Homoterpenes } \\
\hline$\alpha$-Copaene & n.d. & $b$ & $0.9 \pm 0.5$ & $(<1) a b$ & $2.1 \pm 0.4$ & $(1) a$ & n.d. & $b$ & 11.66 & 0.001 \\
\hline$\beta$-Cubebene & n.d. & a & n.d. & a & $1.6 \pm 1.0$ & (1)a & n.d. & a & 2.93 & 0.077 \\
\hline$\beta$-Caryophyllene & n.d. & $b$ & $28.0 \pm 1.8$ & (14)a & $37.3 \pm 18.5$ & (12)a & n.d. & $b$ & 28.71 & $<0.001$ \\
\hline$\alpha$-Humulene & n.d. & $b$ & $15.9 \pm 1.1$ & (8)a & $20.6 \pm 9.6$ & (7)a & n.d. & $b$ & 41.67 & $<0.001$ \\
\hline Germacrene-D & n.d. & $b$ & $8.8 \pm 1.0$ & (4)a & $10.6 \pm 5.1$ & (3)a & n.d. & $b$ & 32.26 & $<0.001$ \\
\hline$\alpha$-Farnesene & n.d. & a & n.d. & a & $1.1 \pm 0.7$ & $(<1) a$ & n.d. & a & 2.89 & 0.079 \\
\hline §-Cadinene & n.d. & $b$ & $1.4 \pm 0.5$ & (1)a & $1.5 \pm 0.6$ & $(<1) a$ & n.d. & $b$ & 5.55 & 0.013 \\
\hline \multicolumn{11}{|l|}{ Sesquiterpenes } \\
\hline 4,8-Dimethyl-1,3,7-nonatriene 6 & $6.9 \pm 1.8$ & $(32) b$ & $57.5 \pm 7.4$ & (29)a & $100.0 \pm 31.2$ & $(32) a$ & $4.1 \pm 0.7$ & $(1) b$ & 45.46 & $<0.001$ \\
\hline \multicolumn{11}{|c|}{ SHIKIMIC ACID /PHENYLPROPANOID PATHWAY PRODUCTS } \\
\hline Indole & n.d. & $\mathrm{b}$ & $15.4 \pm 3.0$ & (8)a & $17.2 \pm 2.9$ & (6)a & $0.3 \pm 0.3$ & $(<1) b$ & 87.98 & $<0.001$ \\
\hline Methyl salicylate & $2.8 \pm 0.2$ & (13)ab & $3.9 \pm 0.2$ & (2)a & $2.7 \pm 0.7$ & (1)ab & $1.8 \pm 0.4$ & $(1) b$ & 3.88 & 0.038 \\
\hline Phenylethyl ester & n.d. & $\mathrm{b}$ & $7.4 \pm 0.9$ & $(4) a$ & $6.7 \pm 1.5$ & $(2) a$ & n.d. & $\mathrm{b}$ & 160.23 & $<0.001$ \\
\hline Benzoic acid, ethyl ester & $1.4 \pm 0.8$ & (6)a & $6.3 \pm 5.2$ & (3)a & $9.4 \pm 2.7$ & (3)a & $0.8 \pm 0.5$ & $(<1) a$ & 2.66 & 0.095 \\
\hline Total & $21.5 \pm 1.3$ & $\mathrm{~b}$ & $199.9 \pm 18.4$ & a & $307.9 \pm 71.7$ & a & $342.3 \pm 180.6$ & $a b$ & 6.29 & 0.008 \\
\hline
\end{tabular}

${ }^{1} N=4$

${ }^{2}$ Mean ng n-octane units $h^{-1} g^{-1}$ of fresh tissue $( \pm S E)$. In parenthesis are percent values based on total amounts. n.d.=not detected (zero values were assigned to non-detectable values for statistical analysis).

${ }^{3} d f=3.12$

${ }^{4}$ For each compound, different letters indicate significant differences between the samples.

${ }^{5}$ Peaks of these volatile compounds co-eluted in the GC.

${ }^{6}$ This compound was misidentified as myrcenone (based on spectral library match) in Rodriguez-Saona et al. (2011). 
variation in volatile blends. The score plot of PC1 versus PC2 shows no overlap among volatile blends of gypsy moth, MeJA, and control treatments, while the mechanically wounded and control treatments overlapped (Figure 2A). The first PC component explained $52.3 \%$ of the variation in volatile blend and separated the gypsy moth and MeJA treatments from the mechanically wounded and control treatments; while the second PC component explained $13.4 \%$ of the variation in the data and separated the gypsy moth from MeJA treatments (Figure 2A).

Two major biosynthetic pathways in the regulation of plant volatiles were influenced by herbivory and MeJA treatments in cranberries; these included the isoprenoid pathway, that resulted in increased emissions of monoterpenes (MANOVA: Wilks' $\lambda<0.001 ; F=4.98 ; P=0.003$ ), sesquiterpenes (Wilks' $\lambda<0.001$; $F=19.77 ; \quad P<0.001$ ), and homoterpenes, and the shikimic acid/phenylpropanoid pathway (Wilks' $\lambda=0.006 ; \quad F=11.94$; $P<0.001)$. In particular, emission of linalool, DMNT, phenylethyl ester, indole, $\beta$-caryophyllene, $\alpha$-humulene, germacrene- $D$, and $\gamma$ cadinene were higher in the gypsy moth and MeJA treatments compared with the other treatments (Table 2). Only $(Z)$-3-hexenyl acetate emissions were greater in the mechanically wounded plants compared with the control plants (Table 2).
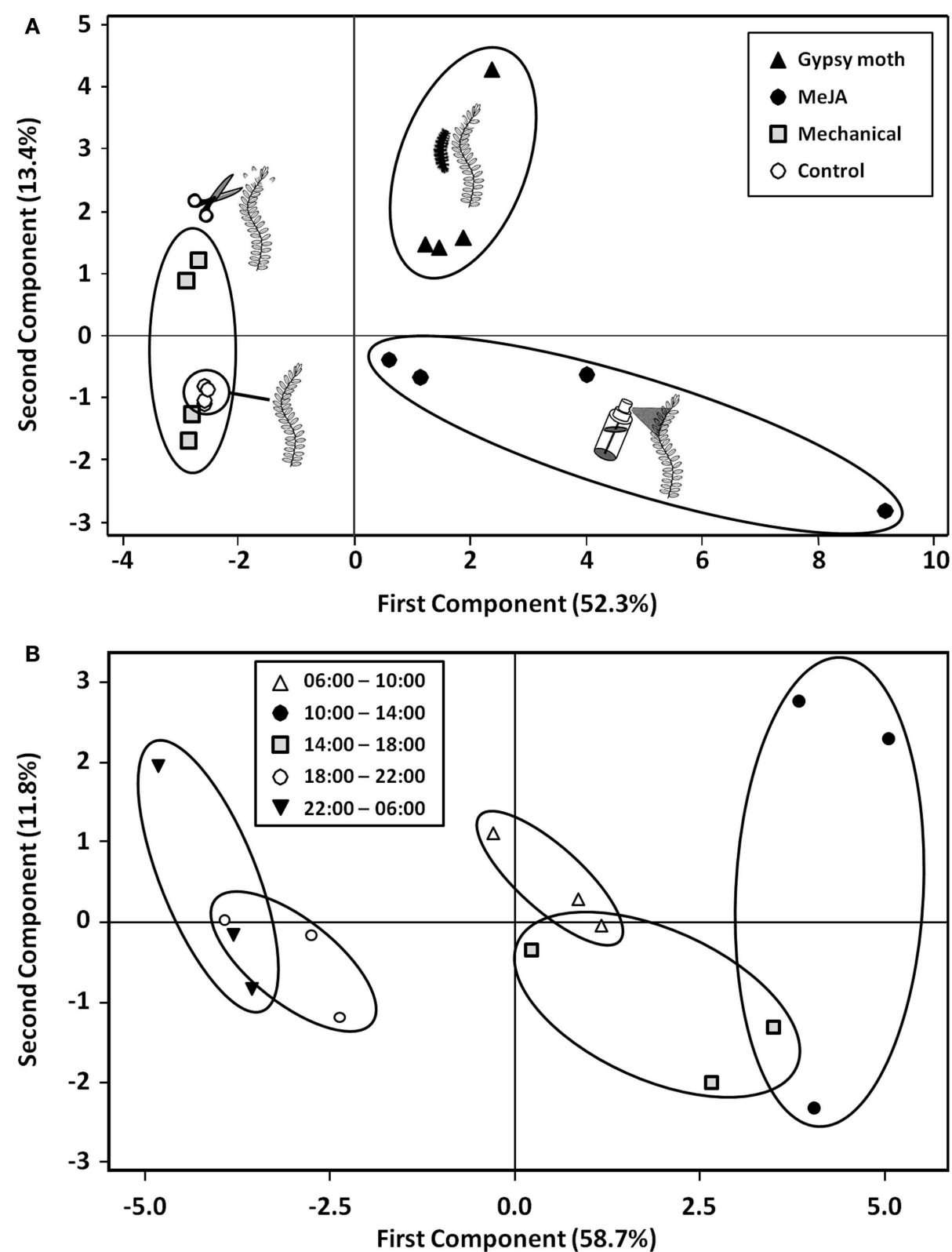

FIGURE 2 | Score plot of principal component analysis (PCA) for (A) the effects of gypsy moth larval feeding, MeJA, and mechanical damage as compared to control plants on the volatile profiles of cranberries
(Vaccinium macrocarpon) leaves, and (B) the effects of time of day on volatile emissions from MeJA-treated plants. Percent variation explained by each principal component is indicated in parenthesis. 
The score plot shows no overlap between volatiles emitted from MeJA-treated cranberry plants at 10:00-14:00 versus those emitted at 06:00-10:00, 18:00-22:00, and 22:0006:00 (Figure 2B). Total volatile emissions from MeJA-treated cranberries peaked between 10:00 and 14:00 and were lowest between 18:00 and 06:00 (Table 3). Emissions of linalool, DMNT, methyl salicylate, phenylethyl ester, indole, $\alpha$-copaene, $\beta$-cubebene, $\beta$-caryophyllene, $\alpha$-humulene, germacrene-D, and $\gamma$ cadinene peaked between 10:00 and 14:00. Only a few compounds (e.g., linalool, DMNT, indole, $\beta$-caryophyllene, $\alpha$-humulene, and germacrene-D) were emitted in detectable amounts at dusk (18:00-22:00) and during the scotophase (in the dark) (Table 3).

\section{ELECTROANTENNOGRAPHY}

We used EAG to determine the antennal activity of a polyphagous herbivore, S. sulfureana, to various cranberry volatiles. The magnitude of the EAG response was significantly different among the tested chemical compounds $(F=2.29, d f=10,129, P=0.017)$. The EAG responses between males and females were, however, not different $(F=1.28, d f=1,129, P=0.261)$, nor the interaction between chemical compound and sex of insect $(F=0.99$, $d f=10,129, P=0.458)$. Antennal responses were greater to $(Z)$ 3 -hexenyl acetate, $\beta$-pinene, linalool, and linalool oxide compared with $\beta$-caryophyllene, $\alpha$-cubebene, $\alpha$-humulene, and $\beta$-farnesene (Figure 3).

\section{ECOLOGICAL LEVEL}

Three herbivores were most abundant on sticky traps; these were: the Sparganothis fruitworm, S. sulfureana, the sharp-nosed leafhopper, Scaphytopius magdalensis Provancher (Hem., Cicadellidae), and the blunt-nosed leafhopper, Limotettix vaccinii (Van Duzee) (Hem., Cicadellidae). The most abundant groups of natural enemies on traps were hoverflies [mainly Toxomerus marginatus (Say)], minute pirate bugs (Orius spp.), spiders, and parasitic wasps.

Table 3 | Time course of volatile emissions from cranberry, Vaccinium macrocarpon, plants sprayed with 1 mM MeJA solution ${ }^{1}$.

\begin{tabular}{|c|c|c|c|c|c|c|c|c|c|c|c|c|}
\hline Compound & \multicolumn{2}{|c|}{$06: 00-10: 00^{2}$} & \multicolumn{2}{|l|}{$10: 00-14: 00$} & \multicolumn{2}{|l|}{ 14:00-18:00 } & \multicolumn{2}{|c|}{ 18:00-22:00 } & \multicolumn{2}{|c|}{ 22:00-06:00 } & $\mathrm{F}^{3}$ & $\boldsymbol{P}$ \\
\hline \multicolumn{13}{|c|}{ LIPOXYGENASE PATHWAY PRODUCTS } \\
\hline (Z)-3-Hexenyl acetate ${ }^{4}$ & $10.3 \pm 0.9$ & $a b$ & $13.1 \pm 0.7$ & a & $33.9 \pm 24.8$ & a & n.d. & $\mathrm{b}$ & n.d. & $b$ & 31.41 & $<0.001$ \\
\hline \multicolumn{13}{|c|}{ Monoterpenes } \\
\hline$\alpha$-Pinene & n.d. & & n.d. & & n.d. & & n.d. & & n.d. & & - & - \\
\hline$\beta$-Pinene & n.d. & $b$ & $4.8 \pm 2.4$ & a & n.d. & $b$ & n.d. & $\mathrm{b}$ & n.d. & $\mathrm{b}$ & 3.98 & 0.035 \\
\hline Myrcene & n.d. & a & $2.7 \pm 2.7$ & a & $2.6 \pm 2.6$ & a & n.d. & a & n.d. & a & 0.75 & 0.58 \\
\hline Eucalyptol/Limonene ${ }^{5}$ & $9.3 \pm 2.9$ & $a b$ & $17.0 \pm 2.6$ & a & $15.0 \pm 2.8$ & a & $1.6 \pm 1.6$ & $b c$ & $0.7 \pm 0.7$ & c & 9.69 & 0.002 \\
\hline Linalool oxide & n.d. & a & $2.5 \pm 2.5$ & a & n.d. & a & n.d. & a & n.d. & a & 1.00 & 0.452 \\
\hline Linalool & $85.7 \pm 20.3$ & a & $135.8 \pm 23.3$ & a & $52.8 \pm 14.4$ & $a b$ & $9.4 \pm 0.9$ & $b c$ & $2.5 \pm 1.3$ & c & 19.85 & $<0.001$ \\
\hline$\beta$-Cubebene & $2.3 \pm 2.3$ & $a b$ & $19.0 \pm 3.9$ & a & $9.8 \pm 4.9$ & $a b$ & n.d. & $b$ & $1.4 \pm 1.4$ & $b$ & 3.84 & 0.038 \\
\hline$\beta$-Caryophyllene & $123.8 \pm 31.0$ & $a b$ & $365.5 \pm 104.3$ & a & $264.2 \pm 34.3$ & a & $75.1 \pm 20.4$ & $a b$ & $43.7 \pm 16.6$ & $\mathrm{~b}$ & 7.63 & 0.004 \\
\hline$\alpha$-Humulene & $66.4 \pm 16.6 .6$ & $a b$ & $193.7 \pm 55.6$ & a & $152.2 \pm 21.5$ & a & $42.5 \pm 10.9$ & $a b$ & $25.9 \pm 10.2$ & $b$ & 6.68 & 0.007 \\
\hline Germacrene-D & $36.0 \pm 10.5 .5$ & $a b$ & $104.9 \pm 48.1$ & a & $74.1 \pm 14.3$ & $a b$ & $18.5 \pm 6.7$ & $a b$ & $9.3 \pm 4.7$ & $b$ & 3.87 & 0.038 \\
\hline$\alpha$-Farnesene & n.d. & a & $14.1 \pm 7.2$ & a & $8.6 \pm 4.3$ & a & n.d. & a & n.d. & a & 3.00 & 0.072 \\
\hline$\delta$-Cadinene & n.d. & $\mathrm{b}$ & $17.7 \pm 6.8$ & a & $10.0 \pm 5.1$ & a & n.d. & $\mathrm{b}$ & n.d. & $\mathrm{b}$ & 9.30 & 0.002 \\
\hline \multicolumn{13}{|l|}{ Homoterpenes } \\
\hline 4,8-Dimethyl-1,3,7-nonatriene & $223.1 \pm 75.2$ & $a b$ & $635.8 \pm 252.4$ & a & $450.3 \pm 128.2$ & $a b$ & $80.2 \pm 34.4$ & $b c$ & $24.5 \pm 10.5$ & c & 11.90 & 0.001 \\
\hline \multicolumn{13}{|c|}{ SHIKIMIC ACID/PHENYLPROPANOID PATHWAY PRODUCTS } \\
\hline Indole & $39.8 \pm 4.8$ & $a b$ & $56.8 \pm 11.2$ & a & $41.1 \pm 12.2$ & $a b$ & $20.0 \pm 3.2$ & $\mathrm{~b}$ & $12.9 \pm 2.8$ & $b$ & 8.72 & 0.003 \\
\hline Methyl salicylate & $9.8 \pm 1.9$ & a & $11.3 \pm 2.8$ & a & $4.5 \pm 2.3$ & $a b$ & n.d. & $\mathrm{b}$ & $1.2 \pm 1.2$ & $a b$ & 6.80 & 0.007 \\
\hline
\end{tabular}

${ }^{1} N=3$. MeJA was applied $16 \mathrm{~h}$ before volatile collections.

${ }^{2}$ Mean ng n-octane units $h^{-1} g^{-1}$ of fresh tissue $( \pm S E)$. n.d.= not detected (zero values were assigned to non-detectable values for statistical analysis).

${ }^{3} d f=4.10$.

${ }^{4}$ For each compound, different letters indicate significant differences between the samples.

${ }^{5}$ Peaks of these volatile compounds co-eluted in the GC. 


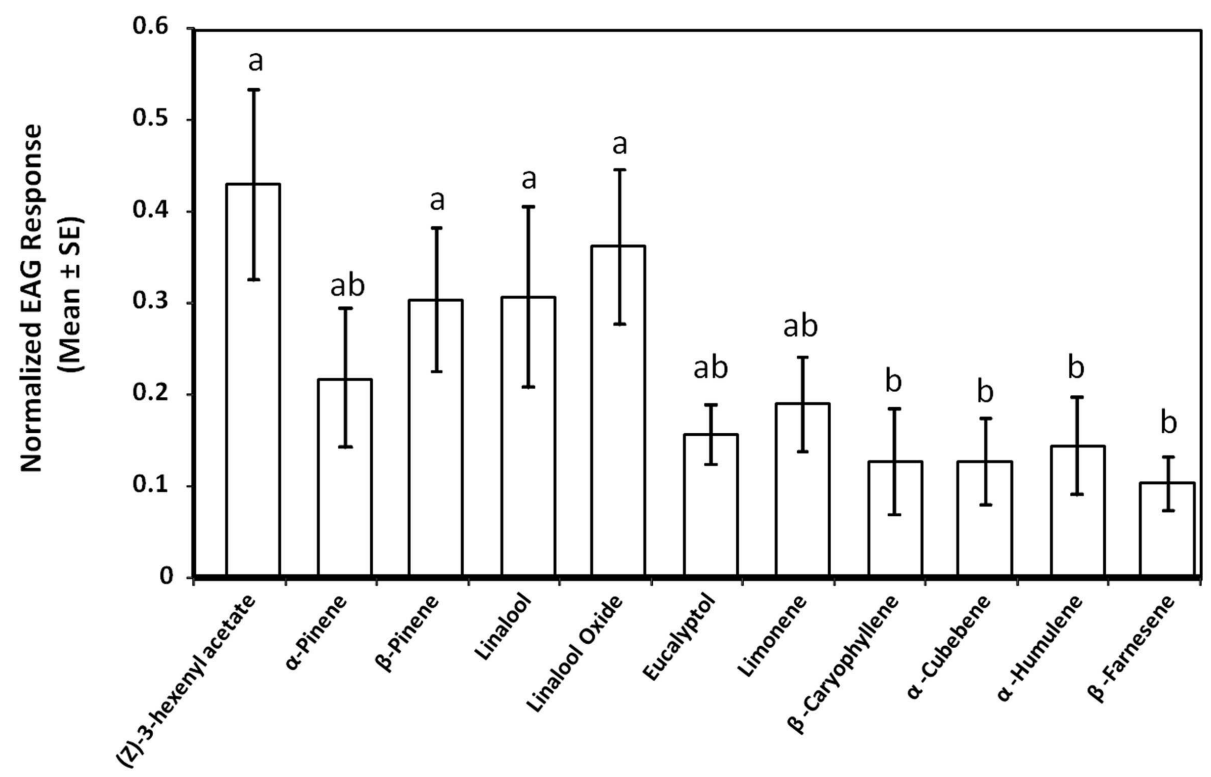

FIGURE 3 | Electroantennogram (EAG) responses of Sparganothis fruitworm, Sparganothis sulfureana, to various cranberry, Vaccinium macrocarpon, leaf volatiles. For analysis, control depolarizations (hexane) were subtracted from the test stimuli values. Different letters indicate significant differences among means $(P \leq 0.05)$. Results of male and female $S$. sulfureana responses were combined in the graph $(N=13-17)$.
MeJA treatment (MANOVA: Wilks' $\lambda=0.86, \quad F=3.36$, $d f=4.81, P=0.014)$, date (Wilks' $\lambda=0.29, F=16.85, d f=8.162$, $P<0.001$ ), but not treatment $\times$ date interaction (Wilks' $\lambda=0.87$, $F=1.39, d f=8.162, P=0.201)$ had a significant negative effect on herbivore abundance on sticky traps. When analyzed in more detail, MeJA had an effect on $S$. sulfureana moths (treatment: $F=6.10, d f=1.84, \quad P=0.016$; date: $F=13.66$, $d f=2.84, \quad P<0.001$; treatment $\times$ date interaction: $F=1.90$, $d f=2.84 ; P=0.156$ ) (Figure $4 \mathrm{~A}$ ), but not on the leafhoppers $L$. vaccinii (treatment: $F=2.10, d f=1.84, P=0.151$; date: $F=30.83, d f=2.84, P<0.001$; treatment $\times$ date interaction: $F=1.06, d f=2.84 ; P=0.352$ ) (Figure $4 \mathbf{B}$ ), or $S$. magdalensis (treatment: $F=1.51, d f=1.84, P=0.223$; date: $F=29.43$, $d f=2.84, \quad P<0.001$; treatment $\times$ date interaction: $F=0.45$, $d f=2.84 ; P=0.638$ ) (Figure 4C).

Abundance of natural enemies on sticky traps were positively affected by MeJA treatment (MANOVA: Wilks' $\lambda=0.68$, $F=9.122, d f=4.81, P<0.001$ ), date (Wilks' $\lambda=0.28, F=17.57$, $d f=8.162, P<0.001$ ), and treatment $\times$ date interaction (Wilks' $\lambda=0.47, F=9.10, d f=8.162, P<0.001)$. When analyzed in more detail, MeJA had a positive effect on parasitic wasps (treatment: $F=36.43, d f=1.84, P<0.001$; date: $F=91.56$, $d f=2.84, P<0.001$; treatment $\times$ date interaction: $F=36.48$, $d f=2.84 ; P<0.001$ ) (Figure $4 \mathbf{F}$ ), but not on the hoverfly $T$. marginatus (treatment: $F=0.31, d f=1.84, P=0.582$; date: $F=4.35, d f=2.84, P=0.016$; treatment $\times$ date interaction: $F=1.91, d f=2.84 ; P=0.155$ ) (Figure 4D), minute pirate bugs (treatment: $F=1.19, d f=1.84, P=0.278$; date: $F=2.67, \quad d f=2.84, \quad P=0.075$; treatment $\times$ date interaction: $F=2.52, d f=2.84 ; P=0.087$ ) (Figure 4E), or spiders (treatment: $F=1.21, d f=1.84, P=0.275$; date: $F=0.08, d f=2.84, P=0.919$; treatment $\times$ date interaction: $F=0.01, \quad d f=2.84 ; \quad P=0.988)$ (Figure 4G).

Sparganothis sulfureana larval mortality was significantly higher when fed foliage from JA-treated cranberry plants as compared with those fed foliage from untreated plants [mean $( \pm$ $\mathrm{SE})$ percent mortality $=\mathrm{JA}: 42.5 \%( \pm 13.5)$; control $=0 \%( \pm 0)$; $F=33.37, d f=1.6, P=0.001]$. Moreover, the negative effects of JA on larval mortality were attributable to the activation of plant defenses by JA and not to direct toxicity because mortality rates were similar on JA-treated $(4 \%)$ and untreated diets $(8 \%)$ $\left(\chi^{2}=0.67 ; d f=1 ; P=0.414\right)$.

\section{DISCUSSION}

Jasmonates such as jasmonic acid and MeJA can serve as an important tool in insect pest management for plant protection against herbivorous pests (Thaler, 1999a; Rohwer and Erwin, 2008; Rodriguez-Saona et al., 2012). Before this can be achieved, however, studies are needed that link the activation of defensive genes by these hormones in plants, the plant's biochemical changes, and the response of both antagonistic and mutualistic organisms to jasmonate-induced plants. In this study, we showed that: (1) herbivory by gypsy moth caterpillars, jasmonate treatment, and mechanical wounding induce, albeit differently, the expression of genes from two different pathways in the biosynthesis of terpene compounds, i.e., the mevalonic acid (MVA) pathway that produces sesquiterpenes and the methylerythritol phosphate (MEP) pathway that leads to monoterpene production (Lichtenthaler et al., 1997; Paré and Tumlinson, 1999; Bartram et al., 2006; Dudareva et al., 2013); (2) herbivore feeding and jasmonate treatment, but not mechanical wounding, induced emissions of monoterpene, homoterpene, and sesquiterpene volatiles; however, blends 


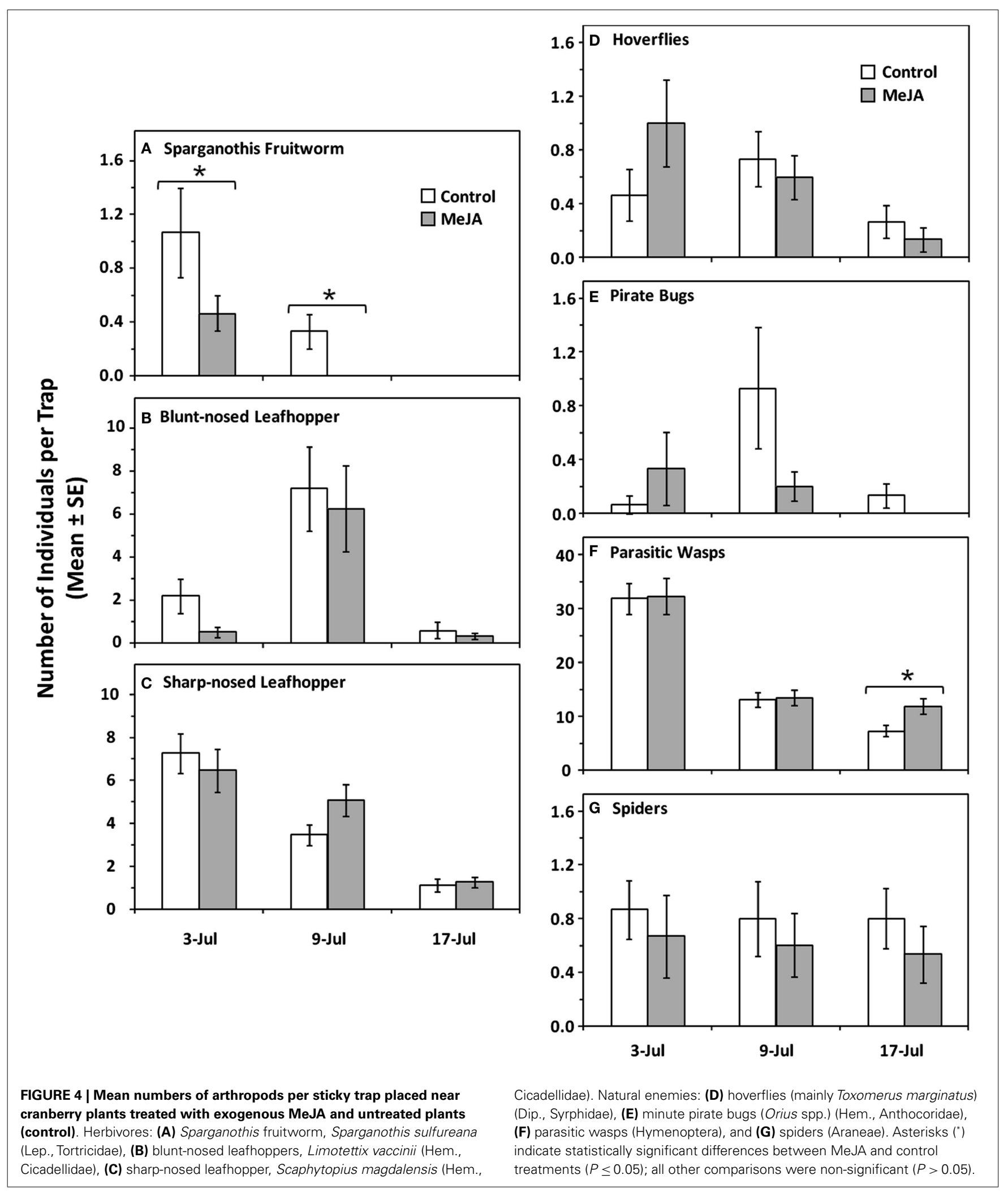

were distinct from one another; and, (3) jasmonate treatment reduced preference and performance of the herbivore S. sulfureana to cranberry plants, and increased colonization by parasitic wasps. Furthermore, S. sulfureana antennae were highly sensitive to inducible monoterpenes, in particular linalool, which might explain the repellence effects of jasmonate-induced plants. 
At the molecular level, expression of genes from two isoprenoid biosynthetic pathways - the MVA and MEP pathways - were activated by gypsy moth feeding, MeJA, and mechanical wounding. Of the eight genes targeted in this study - BCS, FDS, LLS, MDS, NER1, PMK, TPS, TPS21, four responded significantly to gypsy moth larval feeding, MeJA, and mechanical wounding (BCS, LLS, NER1, and TPS21), but to different degrees. Expression of the other four genes (FDS, MDS, PMK, and TPS) did not change. $M D S, P M K$, and FDS are higher up in the terpenoid pathway (Terpenoid Backbone Biosynthesis pathway; KEGG map00900), so the whole pathway is not being induced by larval feeding, MeJA, or mechanical wounding but rather the genes involved in the synthesis of specific terpenes. These data thus indicate that cranberry leaves use pre-formed intermediates to rapidly make specific terpenes. The most dramatic changes in expression of BCS and TPS21 were when treated with MeJA; these genes are in the MVA pathway and the enzymes encoded catalyze the production of $\beta$-caryophyllene and $\alpha$-humulene, respectively. Gypsy mothdamaged and MeJA-treated plants also had elevated expression of $L L S$ and NER1 [LLS is in the MEP pathway and the encoded enzyme catalyzes the synthesis of linalool; NER1 is in the homoterpene biosynthesis pathway and the encoded enzyme catalyzes the synthesis of nerolidol-derived DMNT (Boland et al., 1998)]. Interestingly, for those genes that responded to gypsy moth feeding (BCS, LLS, NER1, and TPS21), the changes in gene expression were also evident in the undamaged tissue on the same plant, indicating a systemic response in gene expression. This was also true in mechanically wounded plants, but only for NER1 and LLS; thus, genes from the MVA pathway do not appear to be expressed systemically by mechanical wounding.

At the biochemical level, volatiles from the MVA pathway (e.g., $\beta$-caryophyllene, $\alpha$-humulene, and germacrene-D) were strongly induced by gypsy moth feeding but not by mechanical wounding in cranberries. Similarly, volatiles from the MEP pathway (e.g., camphene, eucalyptol/limonene, and linalool) were strongly induced by gypsy moth feeding but not or only weakly induced by mechanical wounding. These data suggest that insect-derived elicitors (see Alborn et al., 1997) are required for the induction of terpene emissions in cranberries. In a previous study, RodriguezSaona et al. (2011) found differences in the volatile response to gypsy moth feeding among five cranberry varieties, indicating genotypic variation in the volatile response of cranberries to herbivore feeding. Contrary, they reported similar induction of volatiles by MeJA among these varieties (Rodriguez-Saona et al., 2011). In this study, we also showed that MeJA induces a blend of volatiles in cranberries that was different from herbivore feeding. Other studies have reported a high degree of resemblance, but also some qualitative and quantitative differences, between jasmonate and herbivore-induced volatile profiles (e.g., Dicke et al., 1999; Rodriguez-Saona et al., 2001, 2006; Gols et al., 2003). Altogether, previous data (Rodriguez-Saona et al., 2011) and the present data indicate that signals (i.e., hormones) other than jasmonates might be involved in the emission of HIPVs in cranberries. For example, ethylene was found to interact with JA and the insect-derived elicitor volicitin in the induction of volatile emissions from maize seedlings (Schmelz et al., 2003).
Herbivory and MeJA also induced indole and phenylethyl ester emissions, both products of the shikimic acid pathway (Paré and Tumlinson, 1999), indicating that induced volatiles in cranberries originate mainly from the isoprenoid and shikimic acid pathways. On the other hand, mechanical wounding increased emissions of $(Z)$-3-hexenyl acetate, a product of the lipoxygenase pathway and that is often emitted rapidly in plants as a result of wounding (Paré and Tumlinson, 1999; Chehab et al., 2008).

At the organismal level, jasmonates were involved in the activation of both direct (i.e., plant chemicals that deter or kill the herbivore) and indirect (i.e., chemicals such as HIPVs that attract the herbivores' natural enemies) resistance in cranberries. Host-plant preference and performance were correlated for the polyphagous herbivore $S$. sulfureana: adults were less attracted to, and larval survival was reduced on, jasmonate-induced plants. Table 4 summarizes studies on the effects of jasmonates on herbivorous arthropod performance and preference - we limit this list to studies that used methodologies similar to ours, i.e., jasmonates (JA or MeJA) were sprayed exogenously on plants; thus, investigated only local responses. Out of 37 herbivore-plant interactions reported in these studies, 31 (84\%) showed a negative effect of jasmonates on herbivores, while positive effects accounted for only $8 \%$. Negative effects on the herbivores included lower abundance, performance, colonization, and oviposition on jasmonateinduced plants (Table 4) - likely resulting in increased foraging time and reduced overall fitness; while positive effects included greater abundance, attraction, and oviposition (Table 4). Interestingly, the western flower thrips, Frankliniella occidentalis Pergande, performs poorly on tomato (Thaler et al., 2001) and Chinese cabbage (Abe et al., 2009) induced by JA, whereas it has higher performance on JA-induced cotton (Omer et al., 2001). Likewise, the diamondback moth, Plutella xylostella L., was more attracted for oviposition to JA-treated compared with untreated common cabbage, while it was less attracted to JA-treated than untreated Chinese cabbage (Lu et al., 2004). Thus, the outcome of these interactions can be host-plant dependent.

The mechanism of the repellent effects of MeJA on adult S. sulfureana remains unknown - it is not known which compound(s) is responsible for these effects. Both male and female $S$. sulfureana antennae responded strongly to four cranberry volatiles $[(Z)-3$ hexenyl acetate, $\beta$-pinene, linalool, and linalool oxide]; however, only linalool was emitted in detectable amounts from MeJAtreated cranberry plants during dusk and nighttime (Table 3), when moths are expected to be most active. The more attractive cranberry plants to $S$. sulfureana (controls) emitted low quantities of linalool constitutively; whereas less attractive plants (MeJAtreated) emitted this compound in high amounts (Table 2). This compound has important behavioral effects on other moth species both as an attractant (e.g., Suckling et al., 1996; Raguso et al., 2003) and a repellent (e.g., Kessler and Baldwin, 2001; McCallum et al., 2011), and possibly also on S. sulfureana. Also, the herbivore Spodoptera frugiperda Smith showed an increment in the antennal response (EAG) to linalool at higher doses (Malo et al., 2004). In our study we could not discard the possibility that jasmonates themselves caused the effect. It was also difficult to determine the gender of the moths on sticky cards because of their poor 


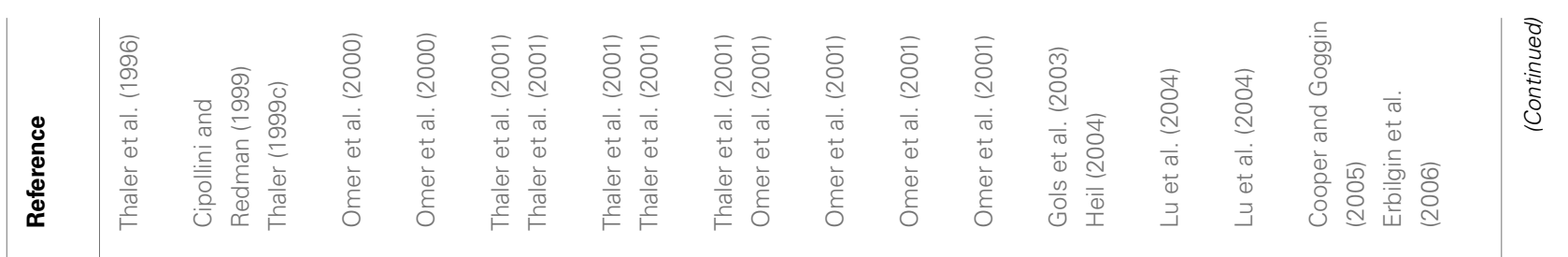

MIIn

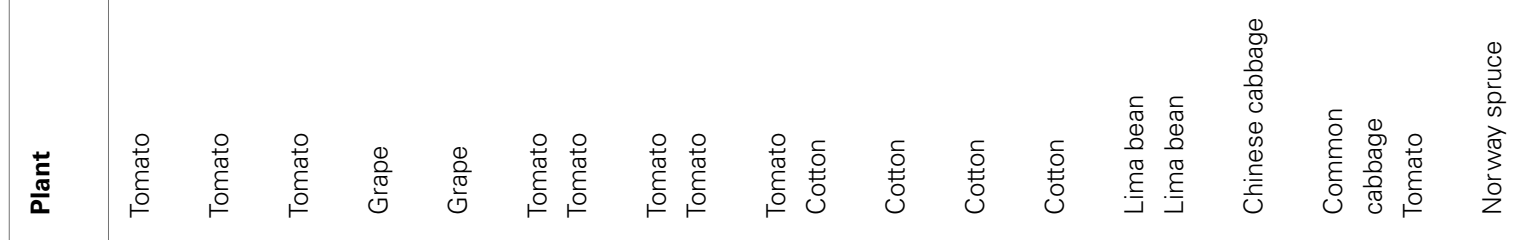

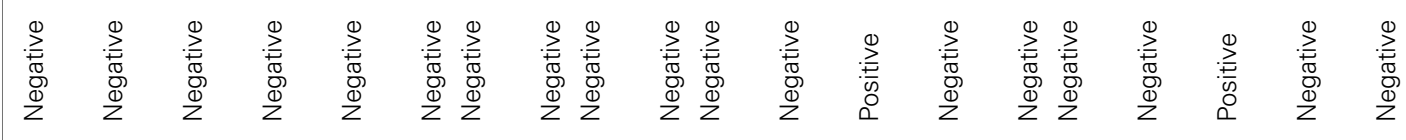

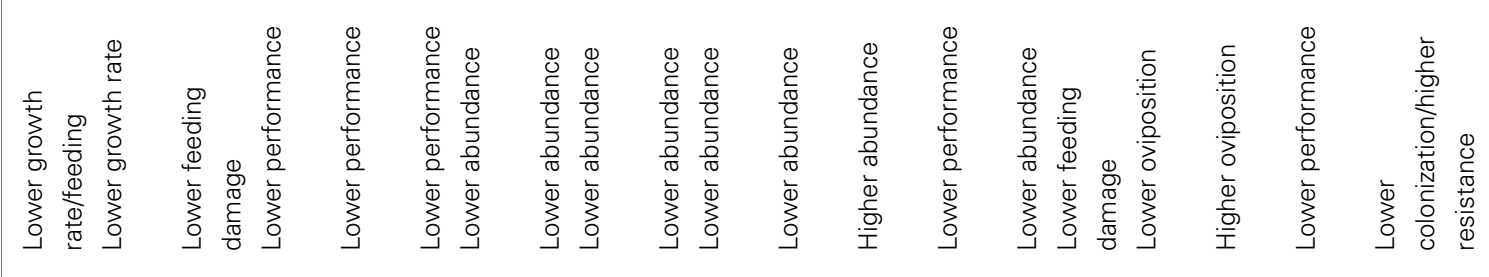

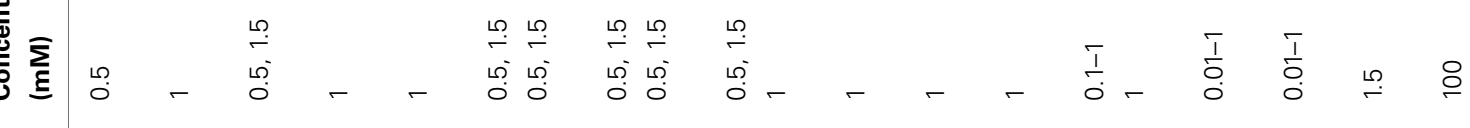

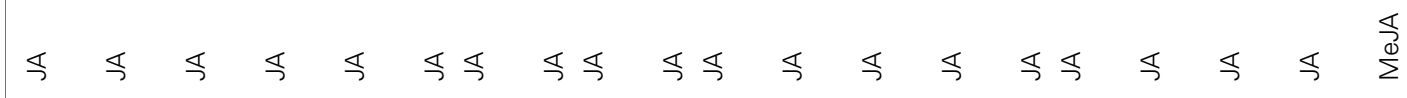

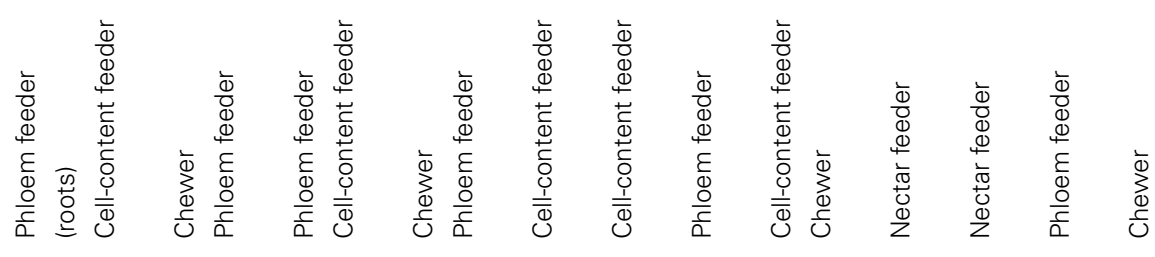

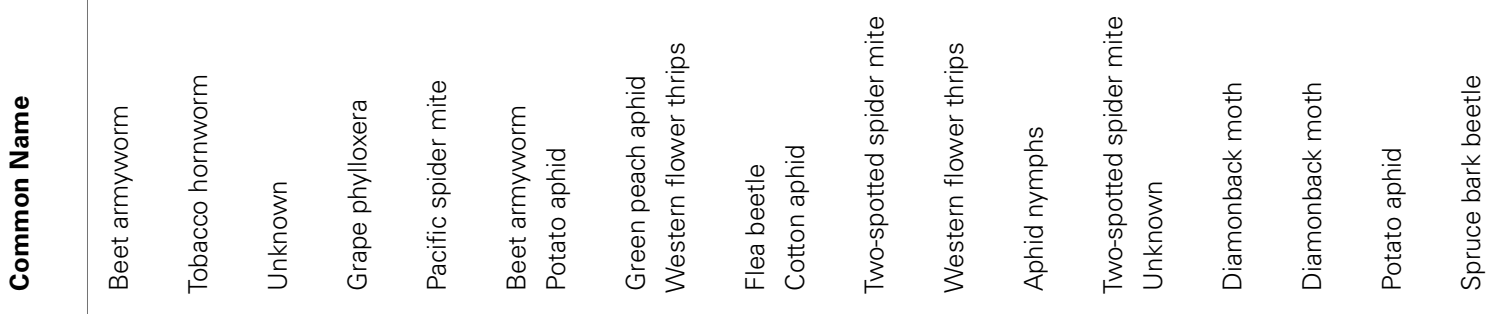

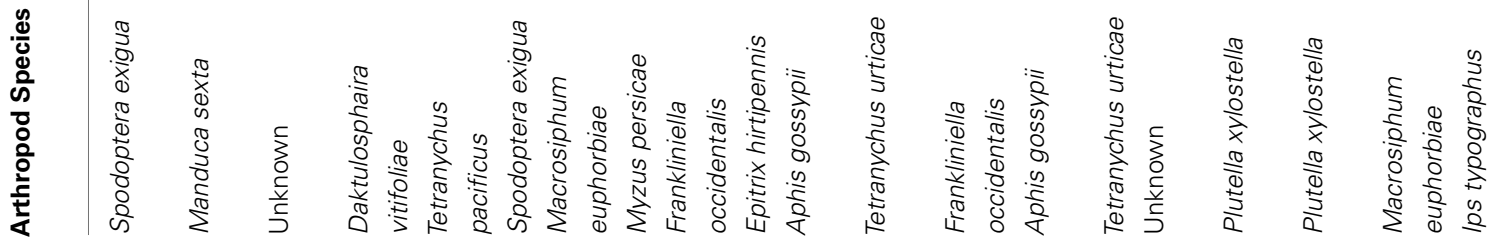




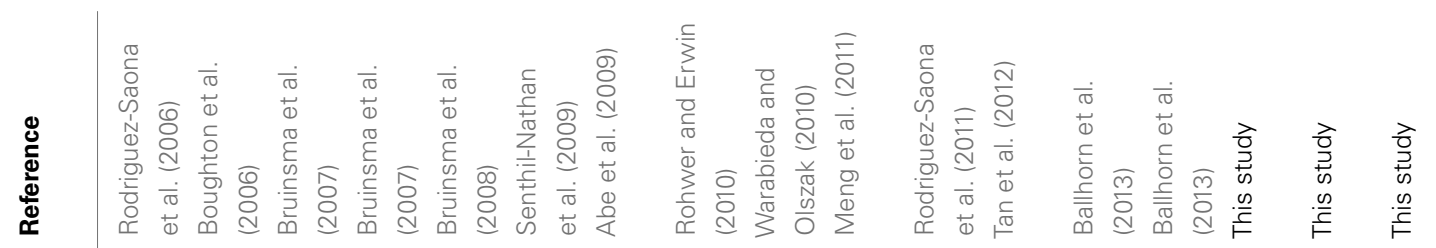
$1 / 111111111110$

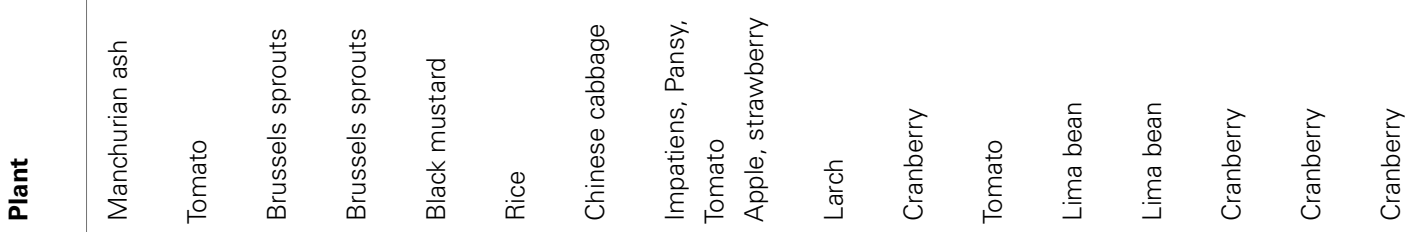
mUnUHUHUHU \|\|\|\|\|\|$\|M\| M$

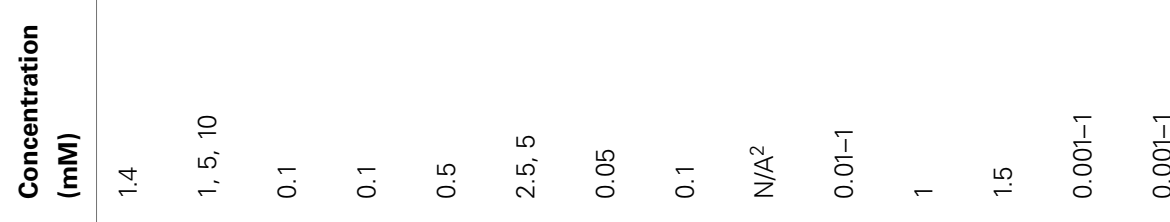

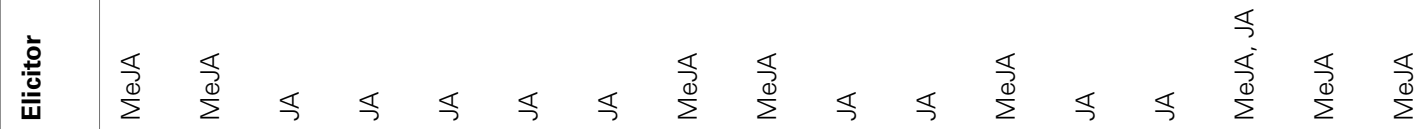

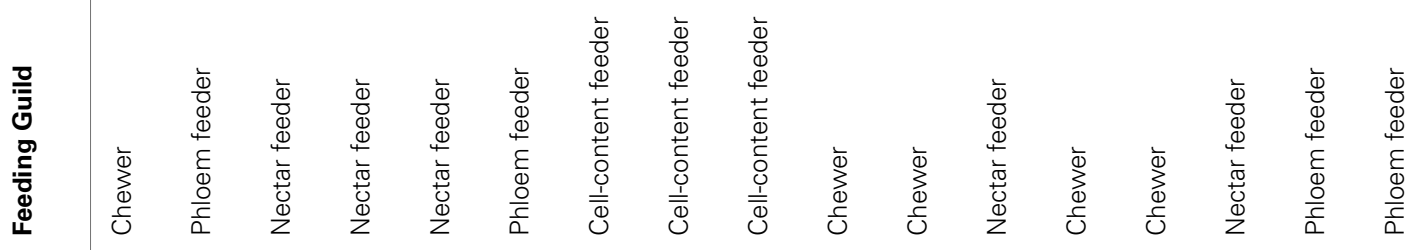

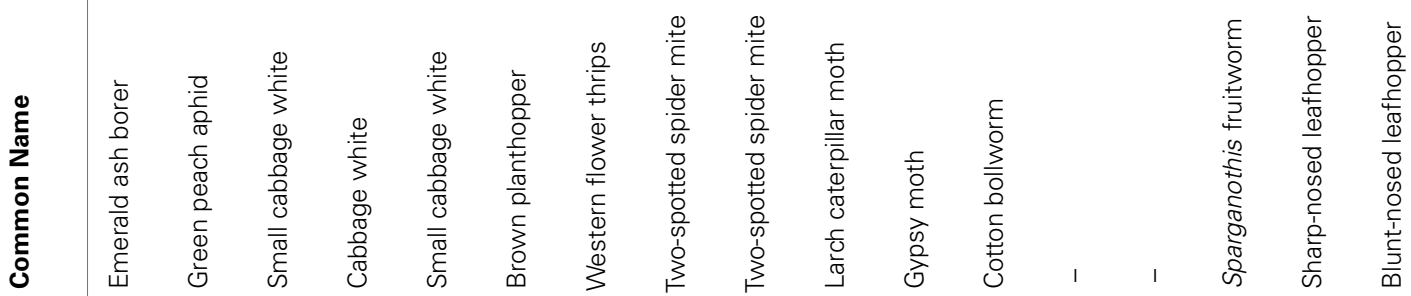

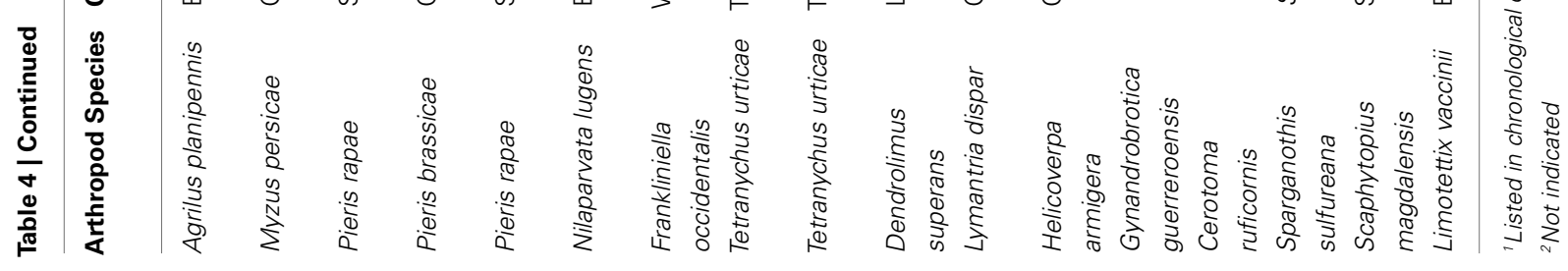




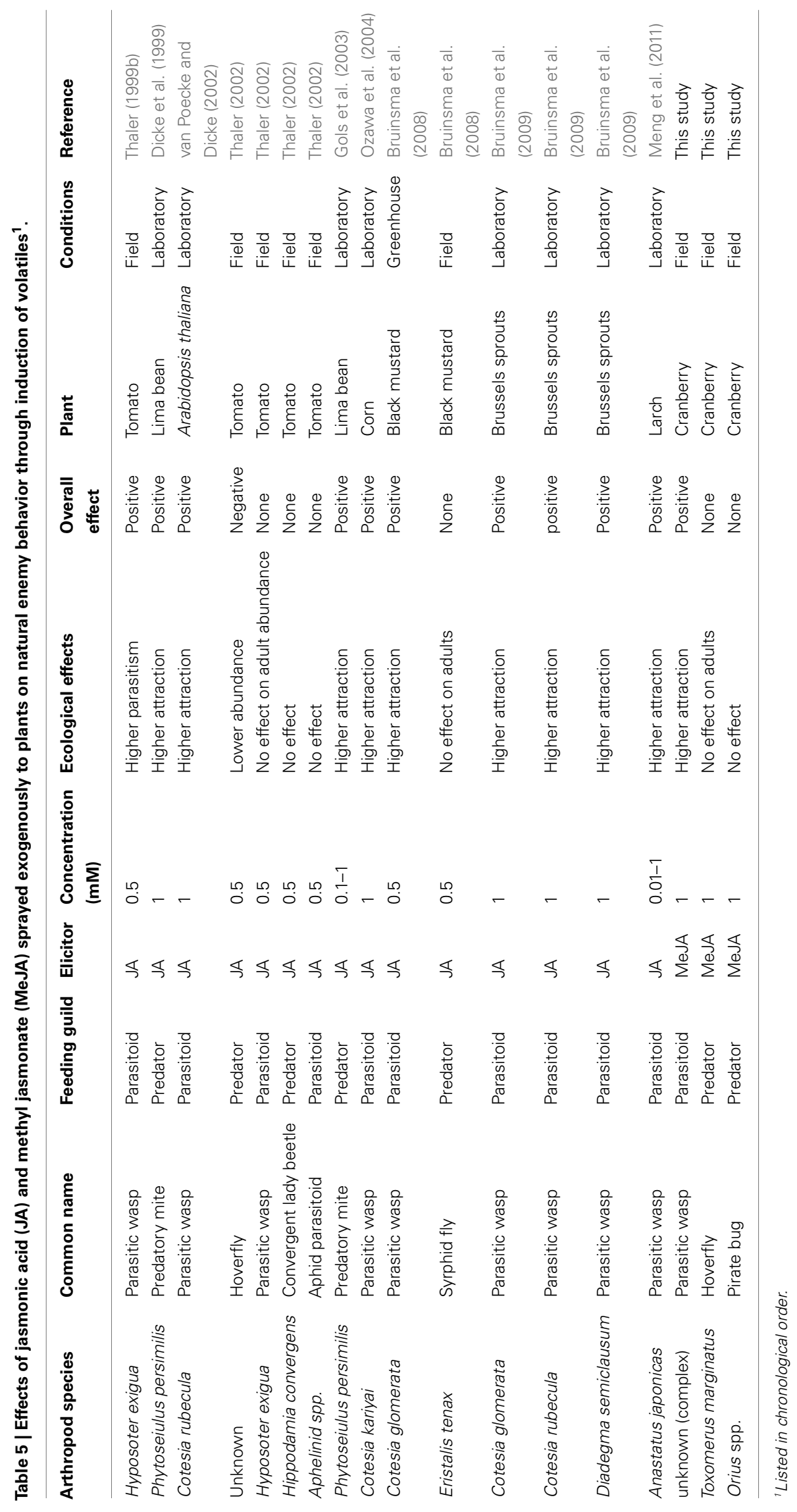


condition, i.e., moths were either too dry or covered with adhesive. Further studies are needed on the dose-dependent effects of linalool and other induced volatile compounds on S. sulfureana foraging behavior, and to determine if gender differences exist in S. sulfureana's response to jasmonate-induced plants and, in particular, the effects of induced volatiles on oviposition.

In contrast to herbivores, the majority (11 out of 18 or $61 \%$ ) of natural enemy-plant interactions involving jasmonate-induce plants were positive (Table 5). All these interactions involved greater attraction to induced plants likely through increases in volatile emissions. Only 1 out of 18 case studies $(6 \%)$ reported a negative effect of jasmonates on natural enemies (Table 5). Thaler (2002) reported reduced number of hoverfly eggs laid on induced plants due to a decrease in aphid (prey) abundance. Interestingly, Thaler (2002) found no effect on adult Hyposoter exiguae Viereck caught on sticky traps placed beneath the canopy of control and JAinduce tomato plants. However, a previous study (Thaler, 1999b) showed higher parasitism of Spodoptera exigua Hübner larvae by $H$. exiguae on JA-induced induced tomato plants, indicating a possible discrepancy between adult attraction and parasitism rate. In the present study, higher numbers of parasitic wasps were caught on sticky traps near MeJA-treated plants than on untreated plants. This attraction coincided with the time of $S$. sulfureana egg laying and larval development; whether this effect translates to greater parasitism of S. sulfureana eggs or larvae (or other herbivore pest) requires further investigation. Additional studies are also needed to address the identity and function of these parasitic wasps.

In summary, this study demonstrates the potential of jasmonates as natural plant protectants against herbivorous pests in cranberries. It also summarizes the overall effects of these phytohormones on herbivorous arthropods and their natural enemies (Tables 4 and 5). These studies show that jasmonates provide protection against herbivores from multiple feeding guilds (chewers, phloem feeders, and cell-content feeders) and increase natural enemy attraction in various agro-ecosystems. However, jasmonate-induced responses can be costly in the absence of herbivores (Baldwin, 1998; Cipollini et al., 2003; but see Thaler, 1999c), or could lead to ecological costs due to trade-offs between resistance to herbivores and pathogens (Felton and Korth, 2000). Further studies are needed to measure these costs in cranberries. Other remaining concerns include: the cost of spraying cranberry fields with MeJA, the length of the effect, and the

\section{REFERENCES}

Abe, H., Shimoda, T., Ohnishi, J., Kugimiya, S., Narusaka, M., Seo, S., et al. (2009). Jasmonate-dependent plant defense restricts thrips performance and preference. BMC Plant Biol. 9:97. doi:10.1186/14712229-9-97

Agrawal, A. A. (1998). Induced responses to herbivory and increased plant performance. Science 279, 1201-1202.

Agrawal, A. A. (2000). Benefits and costs of induced plant defense for Lepidium virginicum
(Brassicaceae). Ecology $\quad 81$ 1804-1813.

Alborn, H. T., Turlings, T. C. J., Jones, T. H., Stenhagen, G., Loughrin, J. H., and Tumlinson, J. H. (1997). An elicitor of plant volatiles from beet armyworm oral secretion. Science 276, 945-949.

Arimura, G.-I., Kost, C., and Boland, W. (2005). Herbivoreinduced, indirect plant defences. Biochim. Biophys. Acta 1734, 91-111.

Averill, A. L., and Sylvia, M. M. (1998). Cranberry Insects of the Northeast.

possibility of inducing all plants and producing a no-choice situation.

In addition, this study integrates multiple levels of biological organization from gene expression to biochemical activation to ecological consequences. Such studies are needed for a better understanding of plant-arthropod interactions (Zheng and Dicke, 2008); yet, we are not aware of any similar studies that investigated the effects of jasmonates (e.g., JA or MeJA) on plants and arthropods at all of these three levels of biological organization (molecular, biochemical, and organismal) in a single study (but see Birkett et al., 2000). Our data show general agreement across all three biological levels of organization: key genes from the terpene pathway were highly expressed in MeJA-treated cranberry plants and terpene volatiles were induced by MeJA, which in turn led to repellency of an herbivore and attraction of certain natural enemies. There were, however, some discrepancies: mechanical wounding induced the local expression of four terpene genes BCS, LLS, NER1, and TPS21 - that encode the enzymes that catalyze the synthesis of $\beta$-caryophyllene, linalool, DMNT, and $\alpha$-humulene, respectively; however, none of these volatiles were emitted in quantities different from unwounded plants. Therefore, we highlight the need of multiple approaches for a more complete assessment on the effects of various environmental stresses that activate the jasmonate signaling - such as herbivory - on plant-insect interactions.

\section{ACKNOWLEDGMENTS}

The authors thank the topic editors for their invitation to submit this contribution and two anonymous reviewers for helpful comments on an earlier draft. Thanks also to Robert Holdcraft, Vera Kyryczenko-Roth, Kristia Adams, Jennifer Frake, and Elizabeth Bender for laboratory and field assistance. Our special thanks to Dr. Thomas Hartman (Rutgers University, Mass Spectrometry Support Facility) and Dr. Hans Alborn (USDAARS, Center for Medical, Agricultural, and Veterinary Entomology) for their assistance in volatile identification, and to Matthew Kramer (USDA-ARS, Biometrical Consulting Service) for the statistical analyses of gene expression and for generating the graph presented in Figure 1. This work was supported by the USDA NIFA Special Grant "Blueberry and Cranberry Disease, Breeding and Insect Management" to Cesar R. RodriguezSaona and James Polashock, and by hatch funds to Cesar R. Rodriguez-Saona.

Amherst: University of Massachusetts Extension.

Baldwin, I. T. (1998). Jasmonateinduced responses are costly but benefit plants under attack in native populations. Proc. Natl. Acad. Sci. U.S.A. 95, 8113-8118.

Ballhorn, D. J., Kautz, S., and Heil, M. (2013). Distance and sex determine host plant choice by herbivorous beetles. PLoS ONE 8:e55602. doi:10.1371/journal.pone.0055602

Bartram, S., Jux, A., Gleixner, G., and Boland, W. (2006). Dynamic pathway allocation in early terpenoid biosynthesis of stress-induced lima bean leaves. Phytochemistry 67, 1661-1672.

Bates, D., Maechler, M., and Bolker, B. (2011). Ime4: Linear Mixedeffects Models Using S4 Classes. $R$ Package Version 0.999375-42. Available at: http://CRAN.Rproject.org/package $=$ lme4.

Beckwith, C. S. (1938). Sparganothis sulfureana Clem., a cranberry pest in New Jersey. J. Econ. Entomol. 31, 253-256.

Bell, R. A., Owens, C. D., Shapiro, M., and Tardiff, J. R. (1981). 
"Development of mass rearing technology," in The Gypsy Moth: Research Toward Integrated Pest Management, eds C. C. Doane and M. L. McManus (Washington: US Department of Agricultural), 599-633.

Birkett, M. A., Campbell, C. A. M., Chamberlain, K., Guerrieri, E., Hick, A. J., Martin, J. L., et al. (2000). New roles for cis-jasmone as an insect semiochemical and in plant defense. Proc. Natl. Acad. Sci. U.S.A. 97, 9329-9334.

Boland, W., Gäbler, A., Gilbert, M., and Feng, Z. (1998). Biosynthesis of C11 and $\mathrm{C} 16$ homoterpenes in higher plants; stereochemistry of the C-Cbond cleavage reaction. Tetrahedron 54, 14725-14736.

Boughton, A. J., Hoover, K., and Felton, G. W. (2006). Impact of chemical elicitor applications on greenhouse tomato plants and population growth of the green peach aphid, Myzus persicae. Entomol. Exp. Appl. 120, 175-188.

Bruinsma, M., Ijdema, H., Van Loon, J. J. A., and Dicke, M. (2008). Differential effects of jasmonic acid treatment of Brassica nigra on the attraction of pollinators, parasitoids, and butterflies. Entomol. Exp. Appl. 128, 109-116.

Bruinsma, M., Posthumus, M. A., Mumm, R., Mueller, M. J., Van Loon, J. J. A., and Dicke, M. (2009). Jasmonic acid-induced volatiles of Brassica oleracea attract parasitoids: effects of time and dose, and comparison with induction by herbivores. J. Exp. Bot. 60, 2575-2587.

Bruinsma, M., Van Dam, N. M., Van Loon, J. J., and Dicke, M. (2007). Jasmonic acid-induced changes in Brassica oleracea affect oviposition preference of two specialist herbivores. J. Chem. Ecol. 33, 655-668.

Chehab, E. W., Kaspi, R., Savchenko, T., Rowe, H., Negre-Zakharov, F., Kliebenstein, D., et al. (2008). Distinct roles of jasmonates and aldehydes in plant-defense responses. PLoS ONE 3:e1904. doi:10.1371/journal.pone.0001904

Cipollini, D. Jr., and Redman, A. (1999). Age-dependent effects of jasmonic acid treatment and wind exposure on foliar oxidase activity and insect resistance in tomato. J. Chem. Ecol. 25, 271-281.

Cipollini, D., Purrington, C. B., and Bergelson, J. (2003). Costs of induced responses in plants. Basic Appl. Ecol. 4, 79-89.

Cooper, W. R., and Goggin, F. L. (2005). Effects of jasmonateinduced defenses in tomato on the potato aphid, Macrosiphum euphorbiae. Entomol. Exp. Appl. 115, 107-115.

De Moraes, C. M., Mescher, M. C., and Tumlinson, J. H. (2001). Caterpillarinduced nocturnal plant volatiles repel conspecific females. Nature 410, 577-580.

Denno, R. F., Peterson, M. A., Gratton, C., Cheng, J., Langellotto, G. A., Huberty, A. F., et al. (2000). Feeding-induced changes in plant quality mediate interspecific competition between sap-feeding herbivores. Ecology 81, 1814-1827.

Dicke, M., Gols, R., Ludeking, D., and Posthumus, M. (1999). Jasmonic acid and herbivory differentially induce carnivore-attracting plant volatiles in lima bean plants. $J$. Chem. Ecol. 25, 1907-1922.

Dicke, M., and Vet, L. E. M. (1999). "Plant-carnivore interactions: evolutionary and ecological consequences for plant, herbivore and carnivore," in Herbivores: Between Plants and Predators, eds H. Olff, V. K. Brown, and R. H. Drent (Oxford: Blackwell Science Ltd), 483-520.

Dudareva, N., Klempien, A., Muhlemann, J. K., and Kaplan, I. (2013). Biosynthesis, function and metabolic engineering of plant volatile organic compounds. New Phytol. 198, 16-32.

Erbilgin, N., Krokene, P., Christiansen, E., Zeneli, G., and Gershenzon, J. (2006). Exogenous application of methyl jasmonate elicits defenses in norway spruce (Picea abies) and reduces host colonization by the bark beetle Ips typographus. Oecologia 148, 426-436.

Farmer, E. E., Johnson, R. R., and Ryan, C. A. (1992). Regulation of expression of proteinase inhibitor genes by methyl jasmonate and jasmonic acid. Plant Physiol. 98, 995-1002.

Felton, G. W., and Korth, K. L. (2000). Trade-offs between pathogen and herbivore resistance. Curr. Opin. Plant Biol. 3, 309-314.

Georgi, L., Johnson-Cicalese, J., Honig, J., Das, S. P., Rajah, V. D., Bhattacharya, D., et al. (2013). The first genetic map of the American cranberry: exploration of synteny conservation and quantitative trait loci. Theor. Appl. Genet. 126, 673-692.

Gols, R., Posthumus, M. A., and Dicke, M. (1999). Jasmonic acid induces the production of gerbera volatiles that attract the biological control agent Phytoseiulus persimilis. Entomol. Exp. Appl. 93, 77-86.

Gols, R., Roosjen, M., Dijkman, H., and Dicke, M. (2003). Induction of direct and indirect plant responses by jasmonic acid, low spider mite densities, or a combination of jasmonic acid treatment and spider mite infestation. J. Chem. Ecol. 29, 2651-2666.

Hare, J. D. (2007). Variation in herbivore and methyl jasmonate-induced volatiles among genetic lines of Datura wrightii. J. Chem. Ecol. 33, 2028-2043.

Hare, J. D. (2011). Ecological role of volatiles produced by plants in response to damage by herbivorous insects. Annu. Rev. Entomol. 56, 161-180.

Heil, M. (2004). Induction of two indirect defences benefits lima bean (Phaseolus lunatus, fabaceae) in nature. J. Ecol. 92, 527-536.

Heil, M. (2010). Plastic defence expression in plants. Evol. Ecol. 24, 555-569.

Hothorn, T., Bretz, F., and Westfall, P. (2008). Simultaneous inference in general parametric models. Biometr. J. 50, 346-363.

Karban, R., and Baldwin, I. T. (1997). Induced Responses to Herbivory. Chicago: University of Chicago Press.

Kessler, A., and Baldwin, I. T. (2001). Defensive function of herbivoreinduced plant volatile emissions in nature. Science 291, 2141-2144.

Lichtenthaler, H. K., Rohmer, M., and Schwender, J. (1997). Two independent biochemical pathways for isopentenyl diphosphate and isoprenoid biosynthesis in higher plants. Physiol. Plant. 101, 643-652.

Lu, Y.-B., Liu, S.-S., Liu, Y.-Q., Furlong, M. J., and Zalucki, M. P. (2004). Contrary effects of jasmonate treatment of two closely related plant species on attraction of and oviposition by a specialist herbivore. Ecol. Lett. 7, 337-345.

Malo, E. A., Castrejón-Gómez, V. R., Cruz-López, L., and Rojas, J. C. (2004). Antennal 20 sensilla and electrophysiological response of male and female Spodoptera frugiperda 21 (Lepidoptera: Noctuidae) to conspecific sex pheromone and plant odors. Ann. Entomol. Soc. Am. 97, 1273-1284.

McCallum, E. J., Cunningham, J. P., Lucker, J., Zalucki, M. P., De Voss, J. J., and Botella, J. R. (2011). Increased plant volatile production affects oviposition, but not larval development, in the moth Helicoverpa armigera. J. Exp. Biol. 214, 3672-3677.

Meng, Z. J., Yan, S. C., Yang, C. P., Jin, H., and Hu, X. O. (2011). Behavioural responses of Dendrolimus superans and Anastatus japonicus to chemical defences induced by application of jasmonic acid on larch seedlings. Scand. J. Forest Res 26, 53-60.

Omer, A. D., Granett, J., Karban, R., and Villa, E. M. (2001). Chemicallyinduced resistance against multiple pests in cotton. Int. J. Pest Manag. 47, 49-54.

Omer, A. D., Thaler, J. S., Granett, J., and Karban, R. (2000). Jasmonic acid induced resistance in grapevines to a root and leaf feeder. J. Econ. Entomol. 93, 840-845.

Ozawa, R., Shiojiri, K., Sabelis, M. W., Arimura, G., Nishioka, T., and Takabayashi, J. (2004). Corn plants treated with jasmonic acid attract more specialist parasitoids, thereby increasing parasitization of the common armyworm. J. Chem. Ecol. 30, 1797-1808.

Paré, P. W., and Tumlinson, J. H. (1999). Plant volatiles as a defense against insect herbivores. Plant Physiol. 121, 325-332.

Price, P. W., Bouton, C. E., Gross, P., McPheron, B. A., Thompson, J. N., and Weis, A. E. (1980). Interactions among three trophic levels: influence of plants on interactions between insect herbivores and natural enemies. Annu. Rev. Ecol. Syst. 11, 41-65.

R Development Core Team. (2012). R: A Language and Environment for Statistical Computing. Vienna: R Foundation for Statistical Computing. ISBN 3-900051-07-0. Available at: URL http://www.R-project.org/

Raguso, R. A., Levin, R. A., Foose, S. E., Holmberg, M. W., and McDade, L. A. (2003). Fragrance chemistry, nocturnal rhythms and pollination 'syndromes' in Nicotiana. Phytochemistry $63,265-284$

Rodriguez-Saona, C. (2011) Herbivore-induced blueberry volatiles and intra-plant signaling. $J$. Vis. Exp. 58, e3440.

Rodriguez-Saona, C., Blaauw, D. R., and Isaacs, R. (2012). "Manipulation of natural enemies in agroecosystems: Habitat and semiochemicals for sustainable insect pest control," in Integrated Pest Management and Pest Control - Current and Future Tactics, eds M. L. Larramendy and S. Soloneski (Rijeka: In Tech), 89-126.

Rodriguez-Saona, C., Crafts-Brandner, S. J., Paré, P. W., and Henneberry, T. J. (2001). Exogenous methyl jasmonate induces volatile emissions in cotton plants. J. Chem. Ecol. 27, 679-695.

Rodriguez-Saona, C., Poland, T. M., Miller, J. R., Stelinski, L. L., Grant, G. G., De Groot, P., et al. (2006). Behavioral and electrophysiological responses of the emerald ash borer, Agrilus planipennis, to induced 
volatiles of Manchurian ash, Fraxinus mandshurica. Chemoecology 16, 75-86.

Rodriguez-Saona, C., Vorsa, N., Singh, A., Johnson-Cicalese, J., Szendrei, Z., Mescher, M., et al. (2011). Tracing the history of plant traits under domestication in cranberries: potential consequences on antiherbivore defences. J. Exp. Bot. 62, 2633-2644.

Rohwer, C. L., and Erwin, J. E. (2008). Horticultural applications of jasmonates: a review. J. Hortic. Sci. Biotech. 83, 283-304.

Rohwer, C. L., and Erwin, J. E. (2010). Spider mites (Tetranychus urticae) perform poorly on and disperse from plants exposed to methyl jasmonate. Entomol. Exp. Appl. 137, 143-152.

Scheiner, S. M. (2001). "MANOVA: multiple response variables and multispecies interactions," in Design and Analysis of Ecological Experiments, 2nd Edn, eds S. M. Scheiner and J. Gurevitch (New York: Oxford University Press), 99-155.

Schmelz, E. A., Alborn, H. T., and Tumlinson, J. H. (2003). Synergistic interactions between volicitin, jasmonic acid and ethylene mediate insectinduced volatile emission in Zea mays. Physiol. Plant. 117, 403-412.

Senthil-Nathan, S., Kalaivani, K., Choi, M.-Y., and Paik, C.-H. (2009). Effects of jasmonic acid-induced resistance in rice on the plant brownhopper, Nilaparvata lugens Stål (Homoptera: Delphacidae). Pestic. Biochem. Physiol. 95, 77-84.

Staswick, P. E., and Lehman, C. C. (1999). "Jasmonic acid-signaled responses in plants," in Inducible Plant Defenses Against Pathogens and Herbivores: Biochemistry, Ecology, and Agriculture, eds A. A. Agrawal, S. Tuzun, and E. Bent (St. Paul: APS Press), 117-136.

Suckling, D. M., Karg, G., Gibb, A. R., and Bradley, S. J. (1996). Electroantennogram and oviposition responses of Epiphyas postvittana (Lepidoptera: Tortricidae) to plant volatiles. New Zeal. J. Crop Hort. Sci. 24, 323-333.

Tan, C.-W., Chiang, S.-Y., Ravuiwasa, K., Yadav, J., and Hwang, S.-Y. (2012). Jasmonate-induced defenses in tomato against Helicoverpa armigera depend in part on nutrient availability, but artificial induction via methyl jasmonate does not. Arthropod Plant Interact 6, 531-541.

Thaler, J., Stout, M., Karban, R., and Duffey, S. (1996). Exogenous jasmonates simulate insect wounding in tomato plants (Lycopersicon esculentum) in the laboratory and field. J. Chem. Ecol. 22, 1767-1781.

Thaler, J. S. (1999a). "Jasmonic acid mediated interactions between plants, herbivores, parasitoids, and pathogens: a review of field experiments in tomato," in Inducible Plant Defenses Against Pathogens and Herbivores: Biochemistry, Ecology, and Agriculture, eds A. A. Agrawal, S. Tuzun, and E. Bent (St. Paul: APS Press), 319-334.

Thaler, J. S. (1999b). Jasmonateinducible plant defences cause increased parasitism of herbivores. Nature 399, 686-688.

Thaler, J. S. (1999c). Induced resistance in agricultural crops: effects of jasmonic acid on herbivory and yield in tomato plants. Environ. Entomol. $28,30-37$.
Thaler, J. S. (2002). Effect of jasmonateinduced plant responses on the natural enemies of herbivores. J. Anim. Ecol. 71, 141-150.

Thaler, J. S., Stout, M. J., Karban, R., and Duffey, S. S. (2001). Jasmonatemediated induced plant resistance affects a community of herbivores. Ecol. Entomol. 26, 312-324.

Tholl, D., and Röse, U. S. R. (2006). "Detection and identification of floral scent compounds," in Biology of Floral Scent, eds N. Dudareva and E. Pichersky (Boca Raton: CRC Press), 3-25.

Turlings, T. C. J., Tumlinson, J. H., and Lewis, W. J. (1990). Exploitation of herbivore-induced plant odors by host-seeking parasitic wasps. Science 250, 1251-1253.

van Poecke, R. M. P., and Dicke, M. (2002). Induced parasitoid attraction by Arabidopsis thaliana: involvement of the octadecanoid and the salicylic acid pathway. J. Exp. Bot. 53 , 1793-1799.

Van Zandt, P. A., and Agrawal, A. A. (2004). Community-wide impacts of herbivore-induced plant responses in milkweed (Asclepias syriaca). Ecology 85, 2616-2629.

Vet, L. E. M., and Dicke, M. (1992). Ecology of infochemical use by natural enemies in a tritrophic context. Annu. Rev. Entomol. 37, 141-172.

Viswanathan, D. V., Narwani, A. J. T., and Thaler, J. S. (2005). Specificity in induced plant responses shapes patterns of herbivore occurrence on Solanum dulcamara. Ecology 86, 886-896.

Walling, L. L. (2000). The myriad plant responses to herbivores. J. Plant Growth Regul. 19, 195-216.
Warabieda, W., and Olszak, R. (2010). Effect of exogenous methyl jasmonate on numerical growth of the population of the two-spotted spider mite (Tetranychus urticae Koch.) on strawberry plants and young apple trees. J. Plant Protect. Res. 50, 541-544.

Zheng, S.-J., and Dicke, M. (2008). Ecological genomics of plantinsect interactions: from gene to community. Plant Physiol. 146, 812-817.

Conflict of Interest Statement: The authors declare that the research was conducted in the absence of any commercial or financial relationships that could be construed as a potential conflict of interest.

Received: 21 February 2013; accepted: 11 April 2013; published online: 29 April 2013.

Citation: Rodriguez-Saona CR, Polashock J and Malo EA (2013) Jasmonate-mediated induced volatiles in the American cranberry, Vaccinium macrocarpon: from gene expression to organismal interactions. Front. Plant Sci. 4:115. doi: 10.3389/fpls.2013.00115

This article was submitted to Frontiers in Plant-Microbe Interaction, a specialty of Frontiers in Plant Science.

Copyright (C) 2013 Rodriguez-Saona, Polashock and Malo. This is an openaccess article distributed under the terms of the Creative Commons Attribution License, which permits use, distribution and reproduction in other forums, provided the original authors and source are credited and subject to any copyright notices concerning any third-party graphics etc. 